\title{
A meta-analysis of induced achievement goals: the moderating effects of goal standard and goal framing
}

\author{
Gera Noordzij ${ }^{1,2}$ D $\cdot$ Lisenne Giel ${ }^{1} \cdot$ Heleen van Mierlo ${ }^{2}$
}

Received: 5 July 2020 / Accepted: 8 January 2021 / Published online: 30 January 2021

(C) The Author(s) 2021

\begin{abstract}
In this paper, we present a meta-analysis of the motivational and performance effects of experimentally induced achievement goals and the moderating effects of goal standard and goal framing; comprising 90 studies which provided 235 effect sizes (11,247 participants). The findings show that, relative to performance-approach and performance-avoidance goals and no-goals, induced mastery-approach goals enhanced performance, but not motivation. With regards to the goal standard used in the inducement, mastery-approach goals related to better performance than performance-approach goals, when mastery-approach goals were based on task-referenced standards or when social comparison was used as a standard for inducing performance-approach goals. With regards to the goal framing used in the inducement, mastery-approach goals were more beneficial when achievement goals were induced by means of goal content. We therefore conclude that goal framing and goal standard should be taken into consideration in achievement goal research and practice.
\end{abstract}

Keywords Induced achievement goals · Meta-analysis $\cdot$ Goal standards · Goal framing

\section{Introduction}

Goals play an important role in motivational processes and outcomes. Over the years, the achievement goal theory (Dweck 1986; Dweck and Leggett 1988; Elliot and McGregor 2001; Nicholls 1984) has been established as an influential framework for understanding individual differences in motivation and performance. A large body of research demonstrates that achievement goals are relevant in everyday

Gera Noordzij

noordzij@euc.eur.nl

1 Erasmus University College, Erasmus University Rotterdam, Nieuwe Markt 1a, 3011 HP Rotterdam, The Netherlands

2 Department of Psychology, Education and Child Studies, Erasmus University Rotterdam, PO Box 1738, 3000 DR Rotterdam, The Netherlands 
achievement settings, including education, work, and sports. Achievement goals refer to "one's dispositional or situational goal preferences in achievement situations" (Payne, Youngcourt, and Beaubien 2007, p. 128). A distinction can be made between mastery and performance goals, further subdivided into approach and avoidance goals (Elliot and McGregor 2001). Mastery-approach goals are aimed at the development of competence and gaining task mastery while mastery-avoidance goals are aimed at avoiding the deterioration of competence and falling short of one's own standards. Performance-approach goals are aimed at the demonstration of competence and the pursuit of outperforming others while performance-avoidance goals are aimed at avoiding the demonstration of incompetence to others and avoiding to be one of the worst performers.

Achievement goal theory has been around for over 30 years, and yet there is still debate on the criteria or standards for performance evaluation that are used when pursuing mastery and performance goals (see, Elliot, Murayama, and Pekrun 2011; Elliot and Trash 2001; Korn and Elliot 2016; Senko and Tropiano 2016). Mastery goals can be based on a task-referenced (i.e., perception of mastery and learning for mastery-approach and avoiding not mastering a task for mastery-avoidance goals) or a self-referenced (i.e., doing better than before for mastery-approach and avoiding deterioration of own's own competences for mastery-avoidance goals) standard to evaluate performance. For example, Elliot, Murayama, and Pekrun (2011) demonstrated that task-based mastery-approach goals were positively and self-referenced mastery-approach goals were not related to motivation. Performance goals can be based on an appearance (i.e., perception of demonstrating competence to others for performance-approach and avoiding the demonstration of incompetence to others for performance-avoidance goals) or a normative (i.e., outperforming others for performance-approach and avoiding being one of the worst performers for performance-avoidance goals) standard to evaluate performance. For example, Hulleman, Schrager, Bodmann, and Harackiewicz (2010) demonstrated in their meta-analysis that appearance performance-approach goals were negatively and normative performance-approach goals were positively related to performance (see also Bardach, Yanagida, Klassen, and Luftenegger 2020).

Up till now, several meta-analyses have been conducted into the correlational relationships between self-reported achievement goals, motivation, and achievement. In sharp contrast, few meta-analyses have been conducted that examine the impact of inducing achievement goals by manipulating goal content or goal climate (i.e., goal framing; Kozlowski and Bell 2006). Goal content is manipulated by providing someone with a straightforward goal to strive for while goal climate is manipulated by making features of the targeted achievement goal salient in the achievement setting. To date, only three published meta-analyses have addressed situationally induced achievement goals and their causal effects on performance (Van Yperen, Blaga, and Postmes 2015; Utman 1997) or motivation (Rawsthorne and Elliot 1999). However, these meta-analyses do so without taking into account the possible moderating effects of the goal standard and the type of goal framing. The current meta-analysis, therefore, aims at meta-analysing studies that induced an achievement goal state to look at their effects on motivation and performance and to what extent these effects are impacted by goal content or goal climate inducement. 
We examined whether the link between achievement goals and motivation and performance could be moderated by goal standard (i.e., the different criteria for performance evaluation) and goal framing (i.e., the inducement of achievement goals by either goal content or goal climate). The aim of this meta-analysis is to get insight in the kind of achievement goals one should pursue, how (i.e., goal framing), and according to which criteria for performance evaluation (i.e., goal standard) achievement goals should be induced to a have a positive effect on motivation and performance. In addition, synthesizing the evidence so far might be helpful in the development and implementation of effective interventions in educational contexts and other achievement domains.

\subsection{Achievement goal theory}

Achievement goal theory is a prominent motivation theory. Originally, Dweck and Leggett (1988) proposed two classes of goals to explain why people engage in achievement behavior: mastery (or learning) goals and performance goals. These two achievement goals originate in part from an individual's implicit theory of ability (Dweck 1986), such that conceiving one's ability as malleable (incremental theory) likely results in the adoption of learning goals, whereas conceiving one's ability as fixed (entity theory) likely results in the adoption of performance goals. Later on, Elliot and McGregor (2001) suggested to incorporate a valence dimension into these two goals, resulting in a 2 (mastery versus performance) $\times 2$ (approach versus avoidance) achievement goal framework.

Achievement goals have been defined and examined either at a trait level (e.g., Button, Mathieu, and Zajonc 1996), a domain level (e.g., at work; see, e.g., VandeWalle 1997a, b), or as a changeable situational characteristic that can be induced (i.e., state-level). Trait and domain-specific achievement goals have been the focus of several meta-analyses (Baranik, Stanley, Bynum, and Lance 2010; Biddle, Wang, Kavussanu, and Spray 2003; Cellar et al. 2011; Huang 2011, 2012; Hulleman et al. 2010; Lochbaum and Gottardy 2015; Payne et al. 2007; Senko and Dawson 2017; Van Yperen, Blaga, and Postmes 2014; Wirthwein, Sparfeldt, Pinquart, Wegerer, and Steinmayr 2013). Overall, results indicate that mastery-approach goals are positively related to motivation and performance in education, sport, and work (e.g., Lochbaum and Gottardy 2015; Payne et al. 2007; Van Yperen et al. 2014). Findings regarding performance-approach goals and motivation and performance are mixed; indicating weak to non-existent effects in education and work (e.g., Payne et al. 2007) and positive effects in sports (e.g., Lochbaum and Gottardy 2015). However, although the effect sizes were less strong, the meta-analysis by Van Yperen et al. 2014 indicated positive effects for performance-approach goals in all domains. In contrast, mastery-avoidance (e.g., Baranick et al. 2010) and performance-avoidance goals (e.g., Payne et al. 2007) both tend to be negatively related to motivation and performance across different domains. 


\subsection{Induced achievement goals as predictors of motivation and performance}

In the literature, the effects of trait, domain, and state-level achievement goals on motivation and performance are assumed to be similar, because "goal orientation dispositions and interventions lead to similar motivational and self-regulatory processes" (Chen and Mathieu 2008, p. 25). For mastery-approach and performanceapproach goals, self-regulation is focused on promoting success, whereas selfregulation for mastery-avoidance and performance-avoidance goals is focused on avoiding failure. The focus on success and the associated positive emotions likely result in more effective self-regulation compared to the focus on avoiding failure and the associated negative emotions. Successful self-regulation, in turn, has been demonstrated to produce higher motivation and enhanced task performance (e.g., Kanfer 1990).

In line with this argumentation, several studies on the inducement of achievement goals (e.g., Van Yperen, Elliot, and Anseel 2009) demonstrated that the inducement of mastery-approach or performance-approach goals was associated with higher levels of motivation and task performance than the inducement of performanceavoidance or mastery-avoidance goals. However, despite their focus on success, performance-approach goals may also result in withdrawal from a task in face of difficulties and failure, making their association with motivation and performance less straightforward than that of mastery-approach goals (cf., Dweck and Leggett 1988). Some studies (e.g., Cianci, Klein, and Seijts 2010a, b) indeed indicate that induced mastery-approach goals have stronger positive effects on motivation and task performance compared to induced performance-approach goals. Studies assessing motivation have used behavioral indicators of motivation, such as free-choice persistence (e.g., Curry, Elliot, Sarrazin, Da Foseca, and Rufo 2002), as well as self-reported motivation (e.g., Steele-Johson, Beauregard, Hoover, and Schmidt 2000, Study 2). Although reliability and validity have been well-established for each of these measures of motivation separately, when combined, behavioral indicators of motivation are often inconsistent with self-reports (Elliott 2004). We therefore included both free-choice persistence and self-reported motivation in our analyses.

Based on the above, we expect that induced mastery-approach and, to a lesser extent, performance-approach goals, result in higher motivation (i.e., free-choice persistence and self-reported motivation) and better task performance compared to induced mastery-avoidance and performance-avoidance goals. In addition, we included no-goal control conditions to investigate the isolated effects of the four achievement goal conditions.

\subsection{Moderators of the motivational and performance effects of induced achievement goals}

Although the extant achievement goal literature (correlational as well as experimental) suggests that approach goals are more beneficial for motivation and performance than avoidance goals, these effects vary substantially across studies (see for example 
Payne et al. 2007 and Hulleman et al. 2010 reporting different effects for performance-approach goals on academic achievement). As such, specific moderating variables might play a role. We propose that the effects of induced achievement goals depend, at least in part, on the nature of the goal and the framing of the manipulation that is used. Specifically, we expect that the outcomes of induced achievement goals might be affected by goal standard and goal framing.

\subsubsection{Goal standard}

A major debate in the achievement goal literature (e.g., Elliot et al. 2011; Hulleman et al. 2010; Senko, Hulleman, and Harackiewicz 2011) concerns the specification of criteria for performance evaluation. Mastery goals are based on self-referenced standards, such that performance is evaluated in terms of intrapersonal criteria (e.g., doing better than one did before, or avoiding the deteroriation of one's own competences). However, several achievement goal theorists (e.g., Elliot et al. 2011) have argued that, in addition to these self-referenced standards, mastery goals can also be based on task-referenced standards, such that performance is evaluated in terms of criteria for task mastery (e.g., mastering and learning a task, or avoiding not mastering and learning a task). Both standards have been used in previous experimental achievement goal studies, albeit mostly implicitly. Examples of task-referenced standards for the inducement of mastery-approach goal in previous studies include: "This session will provide you the opportunity to learn how the brain regulates emotions. When you have completed the study, you will be provided information regarding how well you learned about how the brain regulates emotions. Remember your goal is to learn how the brain regulates emotions...." (Edwards 2010, p. 56) or “..... The session will provide you with the opportunity to get to know these problems and learn how to solve the problems well. You will be informed whether you learned how to solve the problems well." (Bjernebekk et al. 2011, p. 361, Study 2). Examples of self-referenced standards for the inducement of mastery-approach goals are: "To do better than in Trial 1" (Anseel, Van Yperen, Janssen, and Duyck 2011, p. 710) or "...the important thing is that you try as hard as you can and try to improve your performance over time" (Reinboth and Duda 2016, p. 328).

In light of this duality in mastery goal standards, it has been proposed that processing and pursuing a task-referenced mastery goal requires fewer cognitive resources than processing and pursuing a self-referenced mastery goal (Elliot et al. 2011). Evaluation of goal achievement based on a task-referenced standard requires the ability to cognitively represent the task and determine the level at which one has accomplished it. "The self-concept is not salient in such striving, as one's attention remains task-focused" (Elliot et al. 2011, p. 633). Evaluation of goal achievement based on self-referenced standards is more demanding, as it requires a cognitive representation and explicit comparison of two outcomes at the same time (i.e., previous and current outcome). Using a self-referenced standard for evaluation makes the self more salient and one's self-worth might be at stake. In line with this reasoning, Elliot and colleagues (2011) found that task-referenced mastery-approach goals were positively associated with motivation and learning efficacy, whereas self-referenced mastery-approach goals were unrelated to these variables. 
Performance goals, by definition, are based on an other-referenced evaluation standard: Whether or not success is achieved or failure is avoided is evaluated by comparing one's performance to that of relevant others. To date, the literature does not explicitly separate performance goals into different standards in the same way as has been done for mastery goals. Nevertheless, Senko and Tropiano (2016) argue that there are two ways how to define performance goals: Either as demonstrating ability ("appearance goals") or as outperforming others ("normative goals"). In the literature, operationalizations of performance goals have indeed been shown to rely on two different performance evaluation standards: While some rely on a self-presentation standard, others use a social-comparison standard (Elliot 1999; Hulleman et al. 2010; Senko et al. 2011; Urdan and Mestas 2006). When using a self-presentation standard, performance is evaluated based on the impression one wants to make on others. When using a social comparison standard, performance is evaluated based on a comparison with others' performance. Although these observations originate from correlational achievement goal research, the same distinction can be observed in studies on induced achievement goals. The manipulation that was used by Darnon, Harackiewicz, Butera, Mungay, and Quiamzade (2007b, p. 816), for example, reflects a self-presentation standard ("show your competencies"), while Anseel et al. (2011, p. 710) used a manipulation based on a social comparison standard ("do better than others").

Hulleman and colleagues (2010) used Convington's (2000) self-worth contingency perspective to argue that performance goals based on self-presentation standards are more closely tied to one's self-worth and thereby more strongly related to fear of failure, shame, and decreased performance, compared to performance goals based on social comparison standards. Indeed, correlational research tentatively suggests that social-comparison standards result in more beneficial outcomes compared to self-presentation standards (Hulleman et al. 2010; Senko and Dawson 2017). These studies both demonstrated a positive relationship between performanceapproach goals and task performance when performance-approach goals were measured with an emphasis on social-comparison, but a negative relationship with task performance when performance-approach goals were measured with an emphasis on self-presentation items.

\subsubsection{Goal framing}

In an experimental context, there are different ways to induce achievement goals. The framing of achievement goals can be done by means of goal content, goal climate, or a combination of both (Kozlowski and Bell 2006). When goal content is manipulated, the focus is on a specific achievement goal. People are assigned or instructed to adopt an achievement goal for an upcoming task. Avery and Smiley (2011, p. 42), for example, told participants in the mastery-approach goal condition "Your goal whilst performing this memory task is to get to know the task better by focusing on learning how to detect correct number matches well...". In contrast, when goal climate is manipulated the focus is on the achievement climate or context, by manipulating more generally how the task is framed or presented. Teachers, experimenters, team leaders, or coaches may create different goal climates (also 
referred to as goal structures; Meece, Anderman, and Anderman 2006) in an environment through the use of various cues and strategies. For example, in the study by Bereby-Meyer and Kaplan (2005, p. 8), the experiment leader informed participants in the mastery-approach condition that "In this game the idea is to learn from mistakes in order to improve their ability". With this instruction, the experimenter created a climate of learning and improvement. Participants in the performanceapproach condition were told that "Most children who played this game failed to reach the solution, but a few children were very good, and they had an opportunity to show that they were good at the game". In this way, the experimenter created a climate of competition and demonstrating competencies, rather than assigning individual participants a specific individual performance-approach goal.

Kozlowski and Bell (2006) propose that goal climate affects outcomes indirectly, by influencing how intentions are translated into action. This results in a relatively weak but potentially long-lasting effect of achievement goals induced via goal climate manipulations. Goal content, on the other hand, has a more direct effect on action, by influencing the targeted behavior, resulting in a relatively strong effect that materializes relatively quickly.

\subsubsection{Additional moderators}

Apart from goal framing and goal standard, we included the following additional moderators based on theoretical rationale and empirical findings: theoretical framework, country, domain, manipulation check (yes or no), publication status (published papers versus unpublished manuscripts), age, and gender.

We use the "theoretical framework" to distinguish between achievement goal manipulations based on implicit theories of ability (Dweck 1986) and manipulations based on Elliot and McGregor's (2001) $2 \times 2$ framework of achievement goals. Implicit theory manipulations are based on the underlying assumptions of the initial achievement goal theory (Dweck 1986) by distinguishing between a fixed and an incremental theory of ability. Manipulations based on Dweck's implicit theory refer to capabilities and skills one can improve (incremental mindset) or which are more or less stable (fixed mindset). An incremental mindset corresponds to a mastery (approach) goal, while a fixed mindset corresponds to a performance (approach) goal (Dweck 1986). An example of an implicit theory of ability manipulation of performance-approach goals is: 'Your performance on this task is an accurate representation of your ability' (Chen and Mathieu 2008, p. 28). Manipulations based on Elliot and McGregor's (2001) $2 \times 2$ framework of achievement goals focus more directly on goal content or goal climate, without referring to the underlying assumptions of stability or growth. Dewar, Kavussanu, and Ring (2013, p. 5), for example, pointed out that: 'The important thing is that you win this competition', reflecting a performance-approach goal manipulation based on the $2 \times 2$ framework.

Regarding "domain", previous correlational research (e.g., Payne, et al. 2007; Van Yperen et al. 2014) produced divergent effects of achievement goals on performance in different domains (i.e., lab, educational, sport, or work settings). In the current study, we therefore differentiated between lab (i.e., task performance), education, sports, and work settings. 
Regarding "age", Nicholls $(1978,1984)$ argued that only children from the age of 12 on are able to differentiate in their conceptions of ability. Consistent with this argument, Bong (2009) demonstrated a strong correlation between masteryapproach and performance approach goals for younger children (little discrimination) and a decrease in this correlation with increasing age. We therefore also include age (i.e., below the age of 12, between the age of 12 and 18 and above the age of 18) as a moderator.

\section{Method}

\subsection{Literature search}

We conducted an electronic search in the databases of Google Scholar, PsycINFO, PsycArticles, Dissertation Abstracts, and ABI Inform to identify published and unpublished studies from 1980 till 2017 containing an experimental manipulation of achievement goals. We used the following search terms: achievement goal, goal orientation, mastery goal, mastery approach goal, performance goal, performance approach goal, performance avoidance goals, mastery avoidance goal, learning goal, learning goal orientation, task goal, task goal orientation, prove goal, prove goal orientation, performance prove goal, performance prove goal orientation, ego goal, ego goal orientation, ability goal, state goal orientation, task involvement, and ego involvement. We also searched the databases for authors known to be active in achievement goal research (e.g., Biddle, Butler, Duda, Dweck, Elliot, Harackiewicz, Senko, Van Yperen, and VandeWalle). Next, using the abovementioned terms, we conducted a manual search of journals that routinely publish articles based on the achievement goal theory, including the American Educational Research Journal, Journal of Applied Psychology, Journal of Educational Psychology, Journal of Educational Research, Journal of Personality and Social Psychology, Journal of Sport and Exercise Psychology, Motivation and Emotion, Learning and Instruction, Human Performance, Personnel Psychology, and Personality and Social Psychology Bulletin. Moreover, we scanned the Society for Industrial and Organizational Psychology and the American Educational Research Association conference programs for unpublished papers. Finally, the reference lists of a large number of relevant articles (e.g., Linnenbrink-Garci, Tyson, and Patall 2008; Van Yperen et al. 2015) were hand searched for additional eligible articles. This search yielded 278 potential manuscripts for the meta-analysis that we subsequently reviewed on the inclusion criteria (see Table 5).

\subsubsection{Inclusion and exclusion criteria}

Inclusion in our final dataset required that studies:

1. were based on the initial achievement goal theory (Dweck 1986) or the $2 \times 2$ achievement goal theory (Elliot and McGregor 2001) and included an experimental achievement goal manipulation; 
2. were reported in English so that the other inclusion criteria could be checked;

3. included at least one comparison between two achievement goal conditions (i.e., mastery-approach, performance-approach, mastery-avoidance, performanceavoidance goals) or between an achievement goal and a no-goal control condition;

4. included a dependent variable reflecting self-reported motivation (i.e., interest or intrinsic motivation), free-choice persistence (behavioural motivation), or task performance;

5. included sufficient statistical information $(N, M, S D, d, t, F, p)$ to calculate effect sizes.

These inclusion criteria led us to exclude 206 manuscripts, due to one or more of the following reasons: (1) the study focused primarily on goal setting, error training, or self-regulation $(N=95)$; (2) the study included no manipulation or a manipulation that was not primarily based on an achievement goal theory (e.g., feedback manipulation, Senko and Harackiewizc 2002; $N=57$ ); (3) the study did not include motivation or performance as the dependent variable (e.g., social comparison, Darnon, Dompnier, Gillieron, and Butera 2010; $N=33$ ), or (4) the required statistical information could not be obtained, even after contacting the author, or the achievement goal effects were confounded with other experimental manipulations $(N=21)$. The final sample included 56 published articles, 14 dissertations, 1 conference contribution, and 1 master thesis, containing 90 separate studies. Together these studies included 235 effect sizes and 11,247 participants.

\subsubsection{Coding procedure}

The second and last authors independently coded each study on goal standard for mastery and performance goals, goal framing, and theoretical framework. We used Cohen's kappa to examine interrater reliability; all values indicated satisfactory interrater reliability.

Goal standard for mastery goals was coded as self-referenced when manipulations referred primarily to self-improvement (e.g., 'In this game the idea is to learn from mistakes in order to improve ability'; Bereby-Meyer and Kaplan 2005), as task-referenced when manipulations referred primarily to task mastery (e.g., ...try to develop a good command of the new Left-to-Right technique; Senko, Durik, Patel, Lovejoy, and Valentiner 2013, Study 1), or a combination of both when aspects of both self-improvement and task mastery were included (e.g., studies using the TARGET framework; Barkoukis, Tsorbatzoudis, and Grouios 2008; Miles 2010; Rusk 2012); Kappa 0.81.

Goal standard for performance goals was coded as self-presentation when manipulations referred primarily to the impression one wants to make to others (e.g., That is working on the task provides people with an opportunity to demonstrate their logical reasoning skills; Mangos and Steele-Johnson 2001), as social comparison when manipulations referred primarily to a comparison with significant others (e.g., 'The purpose of this project is to compare college students to one another in their ability to solve, our Nina puzzles'; Elliott and Harackiewitz 1994), or as a combination of both when aspects of both making an impression and comparison were included 
(e.g., '... that is, to perform better than the majority of students. In other words, what we ask you here is to show your competencies, your abilities'; Crouzevialle and Butera 2012, Study 1); Kappa 0.92.

Goal framing was coded as goal content when people were assigned, or instructed to adopt, a specific achievement goal for an upcoming task (e.g., Trainees who were assigned performance goals were told that their goal was to demonstrate high performance relative to others; Nordstrom, Wenland, and Williams 1998), as goal climate when manipulations were based on a certain structure or certain cues given by experimenters, teachers or others (e.g., Implementation of mastery approach goal structures in the mathematics classrooms using the TARGET framework and strategies; Miles 2010), or as a combination of both when both goals were assigned or adopted and cues were given (e.g., The learning goal training used goal content as well as goal climate; Noordzij, Van Hooft, Van Mierlo, Van Dam, and Born 2013); Kappa.76.

Theoretical framework, finally, was coded as AGO when the manipulation was based on Elliot and McGregor's (2001) $2 \times 2$ achievement goals (e.g., 'Given that the purpose of the session is to compare college students to each other on how well they perform, its' recommended that you adopt a performance goal'; Lovejoy 2012) or as Implicit Theory when the manipulation was based on Dweck's (1986) implicit theories of ability (e.g., 'We know that participants differ in their creative ability. Participants who do well on this task are more creative than ones who do poorly'; Butler 1995, Study 2); Kappa 0.83.

The three authors met to discuss discrepancies, all of which were resolved by consensus. Furthermore, when possible, each study was coded on country (US/Canada, Europe, or other countries), setting (lab, education, sports or work), inclusion of a manipulation check (yes or no), publication status, age (three categories: < 12 years; between 12 and 18 years; > 12), and gender (percentage of men).

\subsection{Statistical analyses}

Both random-effects and fixed-effects models have been used in previous meta-analyses. However, fixed-effects models are prone to Type I error in significance tests (i.e., overly narrow confidence intervals) both for mean effect sizes and for moderator variables (Hunter and Schmidt 2000; Schmidt, Oh, and Hayes 2009). We therefore used random-effects models for all analyses, assuming that population effect sizes vary randomly between studies and assuming heterogeneity in the effect sizes between studies. The effect size index used in this study was Cohen's $d$. To calculate a global effect size, each effect size was weighted by the inverse of the sum of the between-study variance plus the within-study variance (Hedges and Vevea 1998). To assess statistical heterogeneity in the dataset, the within-class goodness-of-fit statistic $(Q w)$ and Higgins' $I^{2}$ (Higgins and Thompson 2002) of the overall effect size were calculated. We performed subgroup moderator analyses to explore the effects of the moderators on the outcomes of interest. To guarantee the independence assumption, we carried out separate meta-analyses for each outcome and for each comparison (Borenstein, Hedges, Higgins, and Rothstein 2009). If a study used 
multiple trials to examine an outcome measure, the scores of all trials were averaged to obtain one effect size. All analyses were performed with Biostat's Comprehensive Meta-Analysis version 2 (Borenstein, Hedges, Higgins, and Rothstein 2005).

\section{Results}

Table 1 displays the number of effect sizes $(k)$ included in the analysis (for each comparison and outcome measure), mean effect sizes $(d)$, estimated standard errors for the effect sizes (SE), 95\% confidence intervals (CIs), $Z$-scores, $Q w$, and $I^{2}$. In theory, 10 unique goal contrasts could be tested for each outcome, by contrasting each of the five conditions (i.e., mastery-approach, performance-approach, masteryavoidance, performance-avoidance, and no-goal control conditions) in a pairwise manner. In practice, however, most studies did not include all achievement goal conditions and studies also vary in terms of the outcomes that were included. The available data allowed us to test all 10 possible contrasts for task performance, five contrasts for self-reported motivation, and three contrasts for free-choice persistence (see Tables 1, 2, 3).

\subsection{Direct effects of induced achievement goals}

Mastery-approach goals were associated with better performance than performanceapproach, $d=0.28, Z=3.21, p=0.001$, performance-avoidance goals, $d=0.37$, $Z=2.87, p=0.004$, and no-goals, $d=0.21, Z=1.98, p=0.045$. None of the other contrasts were significant, indicating that there were no significant performance differences between mastery-approach goals and mastery-avoidance goals, and between

Table 1 Results for performance

\begin{tabular}{llllllrl}
\hline Comparison & $k$ & $d$ & $S E$ & $95 \% \mathrm{CI}$ & $Z$ & $Q w$ & $I^{2}$ \\
\hline MAp-PAp & 66 & .29 & .09 & $.11 / 46$ & $3.21 * *$ & $811.42^{* *}$ & 91.99 \\
MAp-MAv & 3 & .35 & .21 & $-.06 / .75$ & 1.67 & 4.94 & 59.49 \\
MAp-PAv & 14 & .37 & .13 & $.12 / .62$ & $2.87 * *$ & $42.72 * *$ & 69.57 \\
MAp-Control & 27 & .21 & .11 & $.01 / .42$ & $1.98 *$ & $145.94 * *$ & 82.18 \\
PAp-MAv & 3 & -.14 & .19 & $-.51 / .24$ & -0.71 & 4.38 & 54.36 \\
PAp-PAv & 18 & .17 & .19 & $-.21 / .56$ & 0.89 & $160.93 * *$ & 89.44 \\
PAp-Control & 30 & -.08 & .11 & $-.29 / .13$ & -0.74 & $190.59 * *$ & 84.78 \\
MAv- PAv & 3 & -.33 & .24 & $-.79 / .13$ & 1.41 & $6.06 *$ & 66.98 \\
MAv-Control & 2 & .21 & .24 & $-.27 / .68$ & 0.85 & 2.26 & 55.83 \\
PAv-Control & 8 & .15 & .15 & $-.14 / .44$ & 1.01 & $20.58^{* *}$ & 65.98 \\
\hline
\end{tabular}

$M A p$ mastery-approach goals, $P A p$ performance-approach goals, $M A v$ mastery-avoidance goals, $P A v$ performance-avoidance goals. $k$ number of effect sizes, $d$ mean effect size, $S E$ estimated standard errors, $C I$ confidence interval, $Z$ standard score, $Q w$ within-class goodness-of-fit statistic, $I^{2}$ Higgins $I^{2}$. ${ }^{*} p<.05$, $* * p<.01$ 
Table 2 Results for self-reported motivation

\begin{tabular}{llllllcl}
\hline Comparison & $k$ & $d$ & $S E$ & $95 \% \mathrm{CI}$ & $Z$ & $Q w$ & $I^{2}$ \\
\hline MAp-PAp & 27 & .06 & .17 & $-.26 / .38$ & .36 & $422.59 * *$ & 93.85 \\
MAp-PAv & 4 & .30 & .16 & $-.03 / .62$ & 1.79 & 3.88 & 22.67 \\
MAp-Control & 5 & -.09 & .35 & $-.76 / .59$ & -0.25 & $68.20^{* *}$ & 94.14 \\
PAp-PAv & 4 & .42 & .17 & $.08 / .75$ & $2.44 *$ & 4.16 & 27.92 \\
PAp-Control & 4 & .40 & .40 & $-.39 / 1.19$ & 1.00 & $40.69^{* *}$ & 92.63 \\
\hline
\end{tabular}

$M A p$ mastery approach goals, $P A p$ performance approach goals, $P A v$ performance avoidance goals. $k$ number of effect size, $d$ mean effect size, $S E$ estimated standard errors, $C I$ confidence interval, $Z$ standard score, $Q w$ within-class goodness-of-fit statistic, $I^{2}$ Higgins $I^{2}$.

$* p<.05$,

$* * p<.01$

Table 3 Results for free-choice persistence

\begin{tabular}{llllllll}
\hline Comparison & $k$ & $d$ & $S E$ & $95 \% \mathrm{CI}$ & $Z$ & $Q w$ & $I^{2}$ \\
\hline MAp-PAp & 10 & .26 & .16 & $-.05 / .57$ & 1.64 & $40.60^{* *}$ & 77.83 \\
MAp-PAv & 4 & .69 & .20 & $.30 / 1.08$ & $3.46^{* *}$ & 5.96 & 49.69 \\
PAp-PAv & 4 & .48 & .3 & $-.15 / 1.34$ & 1.49 & $15.84 * *$ & 81.06 \\
\hline
\end{tabular}

$M A p$ mastery approach, $P A p$ performance approach, $P A v$ performance avoidance goals. $k$ number of effect size, $d$ mean effect size, $S E$ estimated standard errors, $C I$ confidence interval, $Z$ standard score, $Q w$ within-class goodness-of-fit statistic, $I^{2}$ Higgins $I^{2}$.* $p<.05, * * p<.01$

any of the performance-approach, performance-avoidance, and mastery-avoidance goals and no-goal control conditions contrasts (see Table 1).

\subsubsection{Motivation}

Mastery-approach goals did not yield significantly stronger motivation (selfreported motivation and free-choice persistence) than performance-approach goals, self-reported motivation: $d=0.06, Z=0.36, p=0.72$, and free-choice persistence: $d=0.26, Z=1.64, p=0.10$. Mastery-approach goals were associated with more freechoice persistence than performance-avoidance goals, $d=0.69, Z=3.46, p=0.001$. Performance-approach goals were associated with more self-reported motivation than performance-avoidance goals, $d=0.42, Z=2.44, p<0.015$. The other contrasts were not significant (see Tables 2 and 3 ).

\subsection{Moderators}

We conducted subgroup analyses to test whether variation among studies in effect sizes was associated with differences in study characteristics. Because of the limited 
number of available effect sizes, these analyses could only be performed on the outcome measure of performance for the mastery-approach versus performanceapproach contrast. The within-class goodness-of-fit statistic $\left(Q_{w}\right)$ was significant for the mastery-approach versus performance-approach contrast for performance, $Q_{w}$ $(65)=811.42, p<0.001, I^{2}=91.99$, indicating that moderators may account for the large heterogeneity in effect sizes (see Table 1).

\subsubsection{Goal standard}

For goal standard, we were interested in the effects of the distinctive standards of evaluation on performance that were used to induce mastery-approach and performance-approach goals. In the moderator analyses, we included studies that used a task-referenced or a self-referenced standard for mastery-approach goal manipulations (i.e., mastery-approach goal standard) and studies that used a self-presentation or a social-comparison standard for performance-approach goal manipulations (i.e., performance-approach goal standard). We excluded studies with manipulations based on multiple standards (i.e. task-referenced plus self-referenced standard or self-presentation plus social-comparison standard; see Table 5 for the studies that used multiple standards).

When manipulations of mastery-approach goals were based on a task-referenced standard for evaluation, mastery-approach goals were more beneficial for performance than performance-approach goals, $d=0.32, Z=2.45, p=0.014$. When the evaluation of mastery-approach goals was based on a self-referenced standard, no significant difference in performance emerged between mastery-approach and performance-approach goals.

When manipulations of performance-approach goals were based on a social comparison standard, mastery-approach goals were more beneficial for performance than performance-approach goals, $d=0.26, \mathrm{Z}=2.48, p=0.013$. When the evaluation of performance-approach goals was based on a self-presentation standard, no difference in performance was found between mastery-approach and performanceapproach goals.

\subsubsection{Goal framing}

For goal framing, we were interested in the distinctive effects of goal content and goal climate on the differences in performance between mastery-approach and performance-approach goals. We therefore excluded studies from the moderation analysis in which goal content and goal climate were manipulated simultaneously (see Table 5 for the studies that used combined goal content and goal climate manipulations). When achievement goals were induced via goal content, masteryapproach goals were more beneficial for performance than performance-approach goals, $d=0.62, Z=3.45, p=0.001$. When achievement goals were induced via goal climate, the mastery-approach versus performance-approach contrast was not significant. 


\subsubsection{Additional moderators}

Regarding theoretical framework, for manipulations based on the achievement goal theory, mastery-approach goals were more beneficial for performance than performance-approach goals, $d=0.35, Z=3.32, p=0.001$. For manipulations based on the incremental theory of ability, no significant difference emerged. For country, mastery-approach goals showed performance benefits compared to performanceapproach goals for studies from the U.S./Canada, $d=0.30, Z=2.17, p=0.030$, and from Europe, $d=0.23, Z=2.01, p=0.044$, but not for other countries. For domain, mastery-approach goals were more beneficial for performance in studies conducted in a lab setting, $d=0.26, Z=2.22, p=0.026$ but not in educational, sport, or work settings. For manipulation check, mastery-approach goals showed performance benefits compared to performance-approach goals in studies that reported a manipulation check, $d=0.44, Z=3.24, p=0.001$, but not in studies without a manipulation check. For publication status, mastery-approach goals showed performance benefits compared to performance-approach goals in published studies, $d=0.27, Z=3.26$, $p=0.001$, but not in unpublished manuscripts. For age, induced mastery-approach goals yielded better performance than performance-approach goals when participants were 18 years or older, $d=0.35, Z=2.95, p=0.003$, but not when the study sample consisted of participants younger than 12 and between 12 and 18 years of age. Finally, performance differences between mastery-approach and performanceapproach goals were not affected by gender (see Table 4 for all results of the moderator analyses).

\subsection{Publication bias}

To assess publication bias for the difference between mastery-approach and performance-approach goals in terms of performance, we looked at the funnel plot, applied the trim-and-fill technique (Duval and Tweedie 2000) to the data, and conducted a fail-safe $\mathrm{N}$ analysis (Rosenthal 1979). Inspection of the funnel plot (see Fig. 1) for the performance difference between induced mastery-approach and performance-approach goals revealed a publication bias on the right side of the funnel plot, $t=2.35, p=0.02$ (Egger, Smith, Schneider, and Minder 1997). Duval and Tweedie's (2000) trim-and-fill technique adjusts the effect size for publication bias. It starts by 'trimming off' the 'asymmetric' side of a funnel plot to achieve a systematical distribution and then replace the trimmed studies and their counterparts around the adjusted center of the funnel plot. With this approach, an adjusted 'trim and fill adjusted' effect size for publication bias can be calculated. When applying this procedure to the overall effect size for the difference in task performance between induced mastery-approach and performance-approach goals, the effect size increases from 0.28 (95\% confidence interval: $0.12 / 0.62$ ) to 0.76 (95\% confidence interval: 0.56/0.96). Duval and Tweedie (2000) have cautioned that this 'trim and fill adjusted' effect size should never be interpreted as the 'true' effect size because it is based on imputed data and has no meaning in itself. It only shows the potential 
Table 4 Moderator analyses: map versus pap goals

\begin{tabular}{|c|c|c|c|c|c|c|c|}
\hline \multirow[t]{2}{*}{ Moderator } & \multicolumn{7}{|c|}{ Between-class effects } \\
\hline & $k$ & $Q_{b}$ & $d f$ & $d$ & $S E$ & $95 \% C I$ & $Z$ \\
\hline MAp standard & & 0.99 & 1 & .22 & .09 & $.05 / .39$ & $2.56^{*}$ \\
\hline 1 Task-referenced & 30 & & & .32 & .13 & $.06 / .57$ & $2.45^{*}$ \\
\hline 2 Self-referenced & 34 & & & .14 & .12 & $-.08 / .37$ & 1.24 \\
\hline PAp standard & & 0.84 & 1 & .18 & .07 & $.06 / .31$ & $2.82 * *$ \\
\hline 1 Self-presentation & 21 & & & .14 & .08 & $-.03 / .30$ & 1.63 \\
\hline 2 Social comparison & 37 & & & .26 & .10 & $.05 / .46$ & $2.48^{*}$ \\
\hline Goal framing & & $4.35^{*}$ & 1 & .31 & .10 & $.10 / .52$ & $3.05^{* *}$ \\
\hline 1 Content & 19 & & & .62 & .18 & $.27 / .97$ & $3.36 * *$ \\
\hline 2 Climate & 37 & & & .16 & .13 & $-.08 / .41$ & 1.39 \\
\hline Theoretical framework & & $5.49 *$ & 1 & .17 & .07 & $.03 / .31$ & $2.36^{*}$ \\
\hline $1 \mathrm{AGT}$ & 56 & & & .35 & .11 & $.14 / .56$ & $3.32 * *$ \\
\hline 2 Implicit theory & 10 & & & .01 & .10 & $-.19 / .20$ & 0.10 \\
\hline Country & & 0.18 & 2 & .27 & .08 & $.12 / .43$ & $3.43 * *$ \\
\hline 1 U.S/Canada & 40 & & & .30 & .14 & $.03 / .58$ & $2.17 *$ \\
\hline 2 Europe & 19 & & & .23 & .12 & $.01 / .46$ & $2.01 *$ \\
\hline 3 Other & 7 & & & .30 & .17 & $-.03 / .62$ & 1.77 \\
\hline Domain & & 1.64 & 3 & .25 & .07 & $.10 / .40$ & $3.35^{* *}$ \\
\hline 1 Lab setting & 47 & & & .26 & .12 & $.03 / .49$ & $2.22 *$ \\
\hline 2 Education & 11 & & & .20 & .12 & $-.03 / .43$ & 1.73 \\
\hline 3 Sport & 6 & & & .95 & .51 & $-.05 / 1.96$ & 1.87 \\
\hline 4 Work & 2 & & & .25 & .18 & $-.11 / .60$ & 1.37 \\
\hline Manipulation check & & 5.93 & 1 & .15 & .06 & $.04 / .25$ & $2.65^{* *}$ \\
\hline 1 Yes & 40 & & & .44 & .14 & $.12 / .17$ & $3.24 * *$ \\
\hline $2 \mathrm{No}$ & 25 & & & .10 & .06 & $-.03 / .22$ & 1.56 \\
\hline Publication status & & 0.02 & 1 & .27 & .08 & $.11 / .43$ & $3.35^{* *}$ \\
\hline 1 Paper & 52 & & & .27 & .08 & $.11 / .44$ & $3.26^{* *}$ \\
\hline 2 Unpublished man & 14 & & & .23 & .30 & $-.36 / .81$ & 0.76 \\
\hline Age group & & 2.76 & 2 & .20 & .07 & $.07 / .33$ & $3.07 * *$ \\
\hline 1 age $<.12$ & 11 & & & .20 & .13 & $-.05 / .45$ & 1.57 \\
\hline 2 age between $12-18$ & 7 & & & .10 & .10 & $-.09 / .29$ & 1.01 \\
\hline 3 age $>18$ & 48 & & & .53 & .12 & $.12 / .59$ & $2.95 * *$ \\
\hline Gender (percentage men) & 57 & & & .00 & .01 & $-.01 / .01$ & 0.05 \\
\hline
\end{tabular}

$M A p$ mastery approach goals, $P A p$ performance approach goals. $k$ number of effect size, $Q b$ betweenclass goodness-of-fit statistic, $d f$ degrees of freedom, $d$ mean effect size, $S E$ estimated standard error, $C I$ confidence interval, $Z$ standard score. $* p<.05$, ** $p<.01$

impact of missing studies; in our case this means that the effect size of 0.28 might be an underestimation of the 'true' effect size because of publication bias. The failsafe $\mathrm{N}$ analysis for the overall difference between induced mastery-approach and performance-approach goals in their effect on performance was 926, suggesting that 
Funnel Plot of Standard Error by Std diff in means

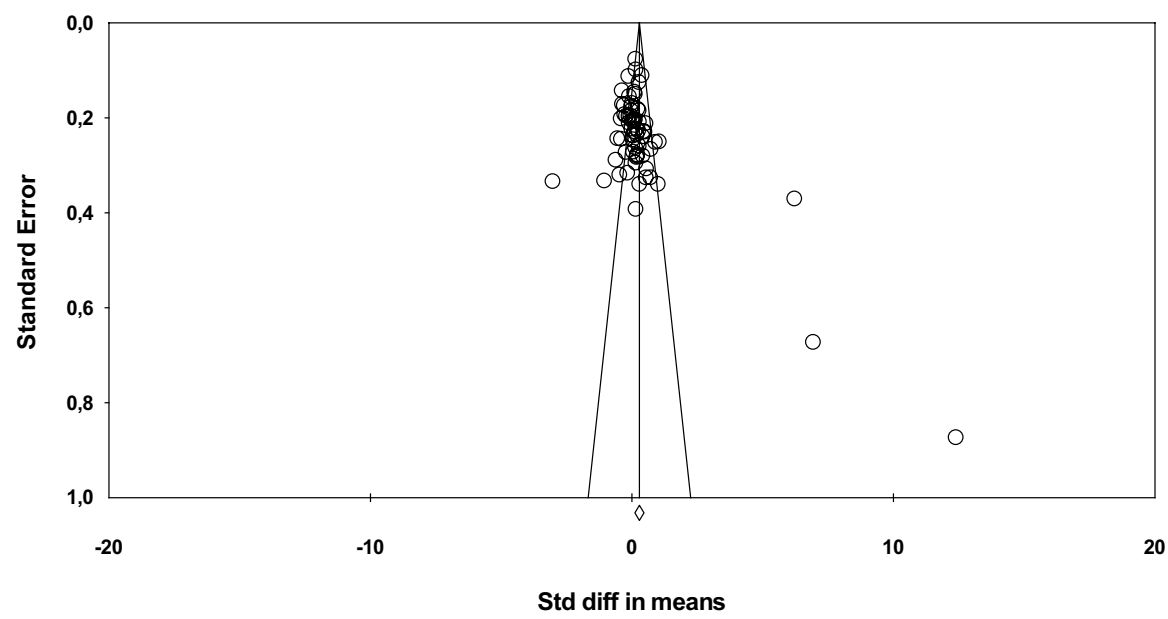

Fig. 1 Funnel plot for the difference between mastery-approach and performance-approach goals on performance

926 additional studies with no effect should exist in the population of studies for this result of the meta-analysis to be non-significant.

For the other significant contrasts on performance (i.e., between masteryapproach and performance-avoidance goals, and between mastery-approach goals and no-goal control), inspection of the funnel plots revealed a publication bias on the right side $(t=2.30, p=0.04$ and $t=2.11, p=0.046$, resp.). However, "trimming off" did not result in an adjustment of the effect size.

Finally, for motivation, the only significant contrast for free choice motivation between mastery-approach and performance-avoidance goals and for self-reported motivation between performance-approach and performance-avoidance goals revealed no significant publication bias $(t=0.41, p=0.36$ and $t=1.23, p=0.17$, resp.). Based on the results, publication bias seems an unlikely explanation of the outcomes of our meta-analysis (Table 5).

\section{Discussion}

With the present meta-analysis, we aimed at meta-analysing all studies on induced state achievement goals by including a comprehensive sample of 235 individual effect sizes from 90 separate studies. We examined the differences between induced mastery-approach, performance-approach, mastery-avoidance, and performanceavoidance achievement goals and no-goals in terms of motivation and performance as well as the extent to which the differences in performance were contingent on goal standard, goal framing, and various additional moderators. 


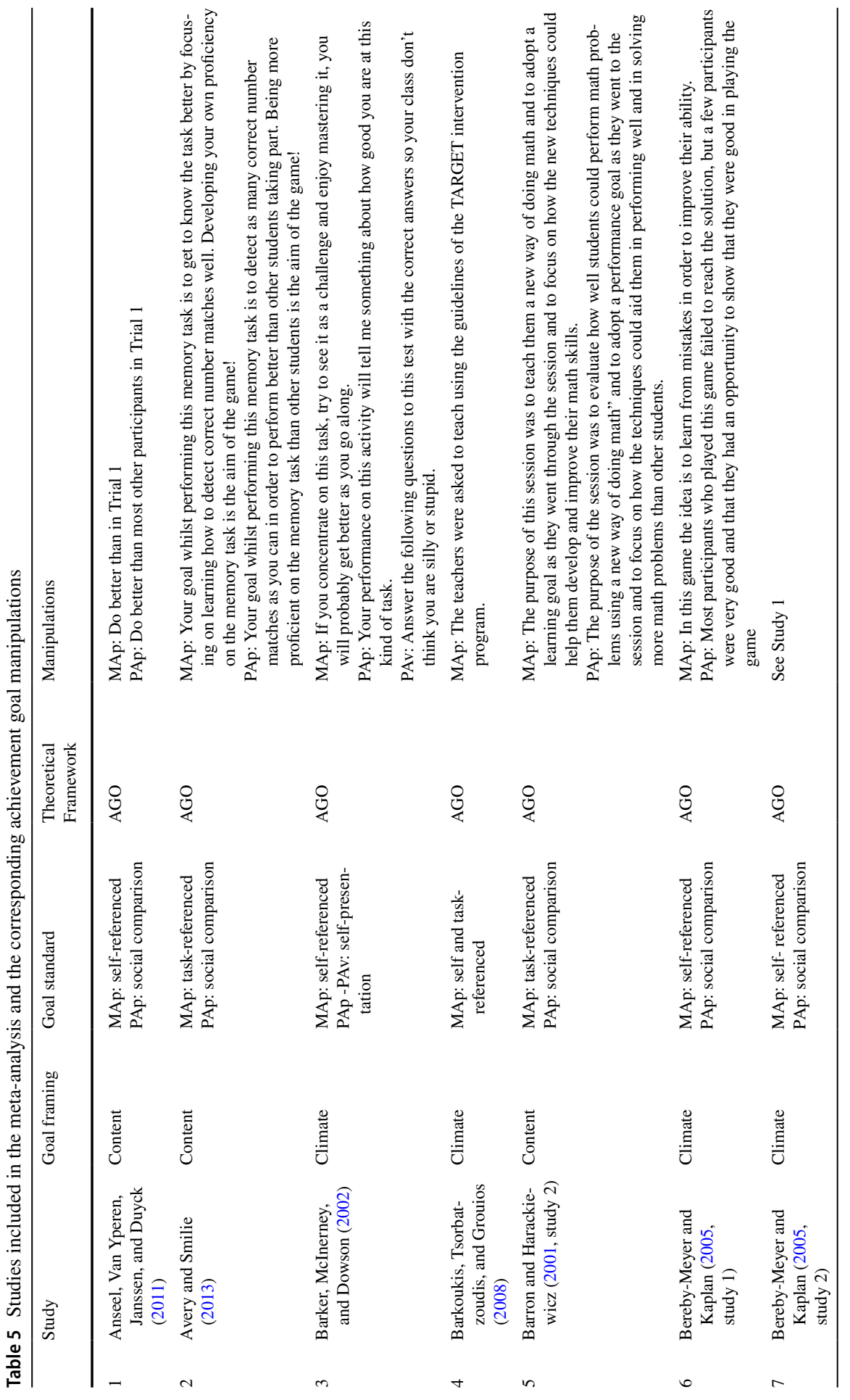




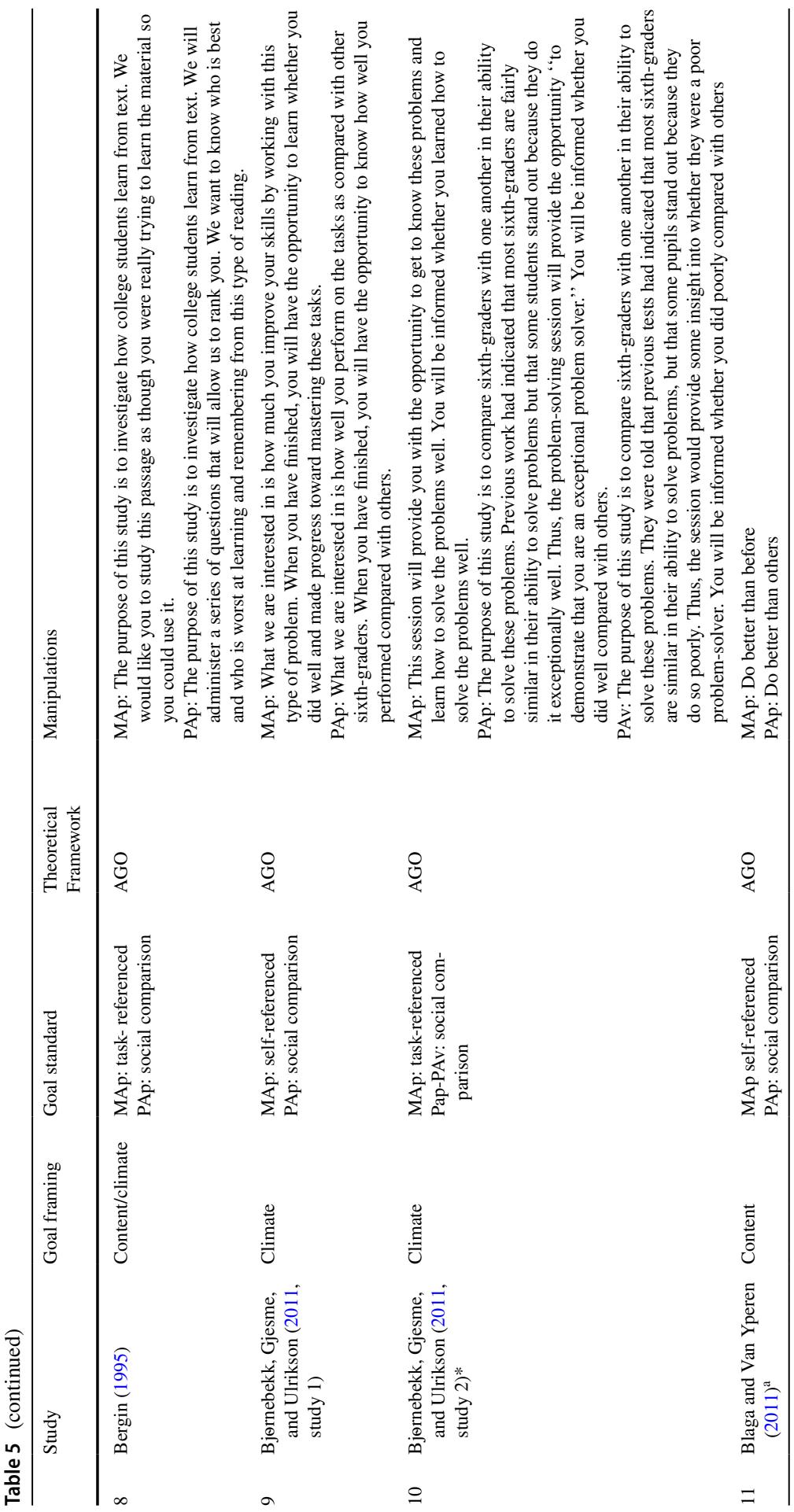




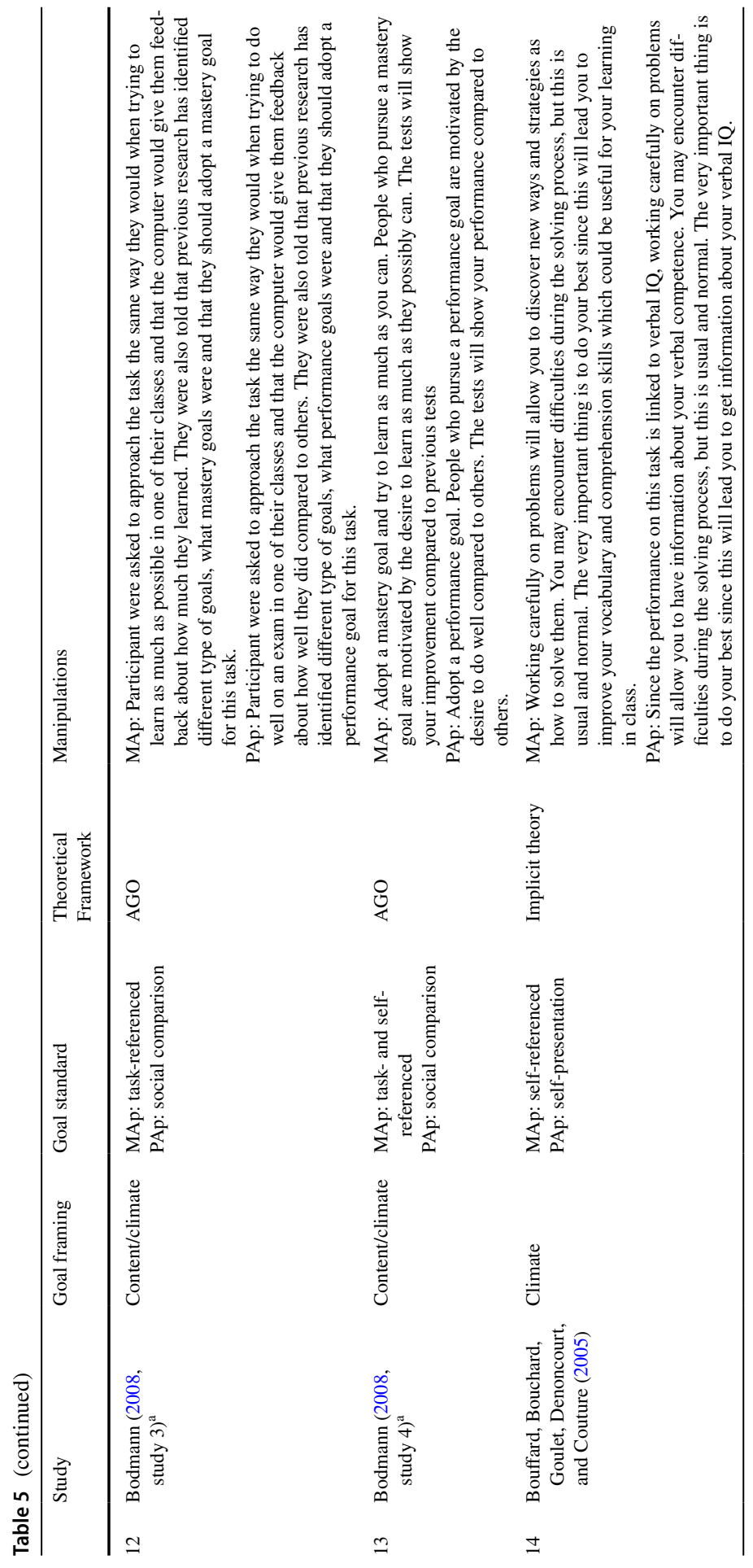




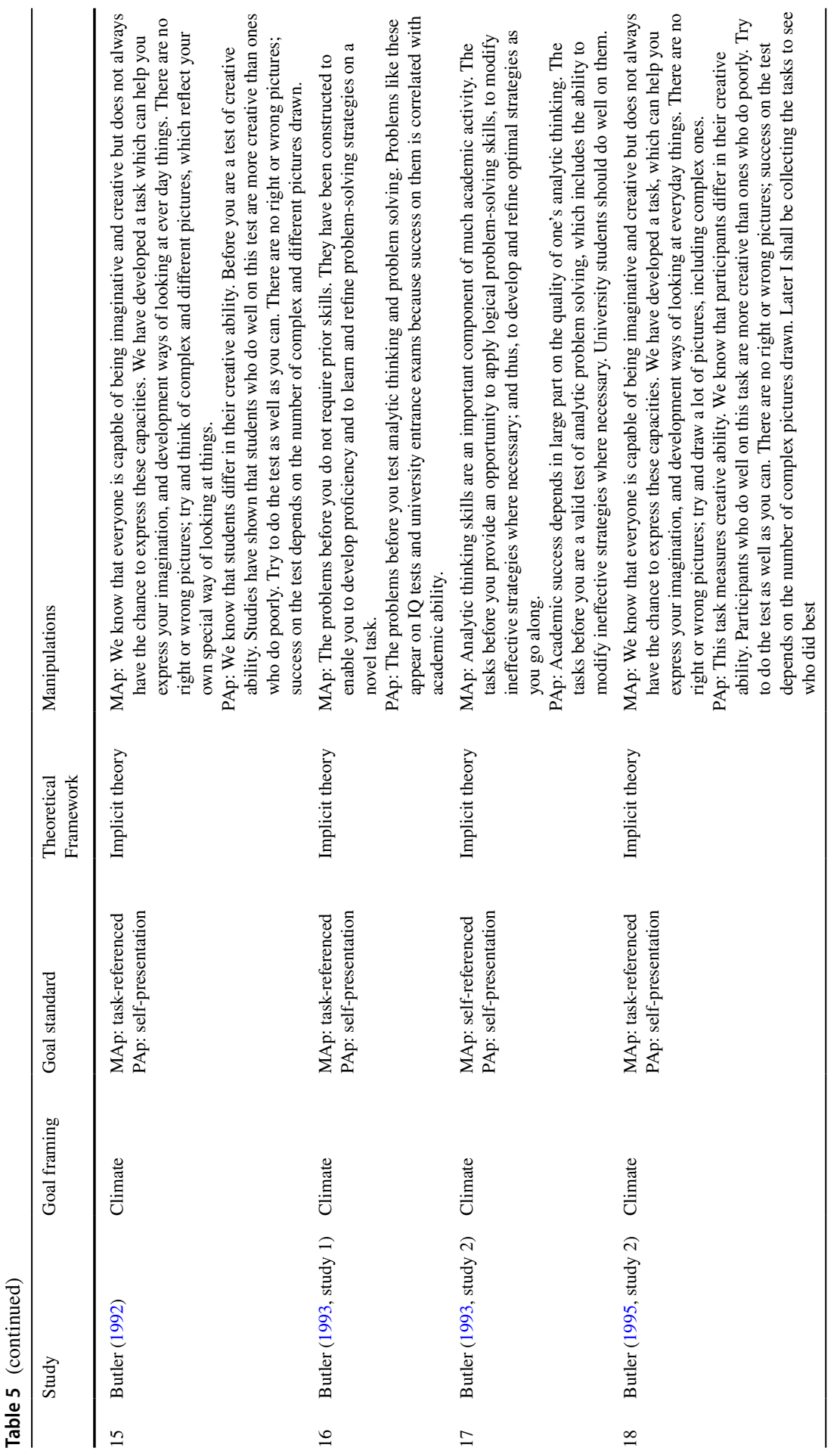




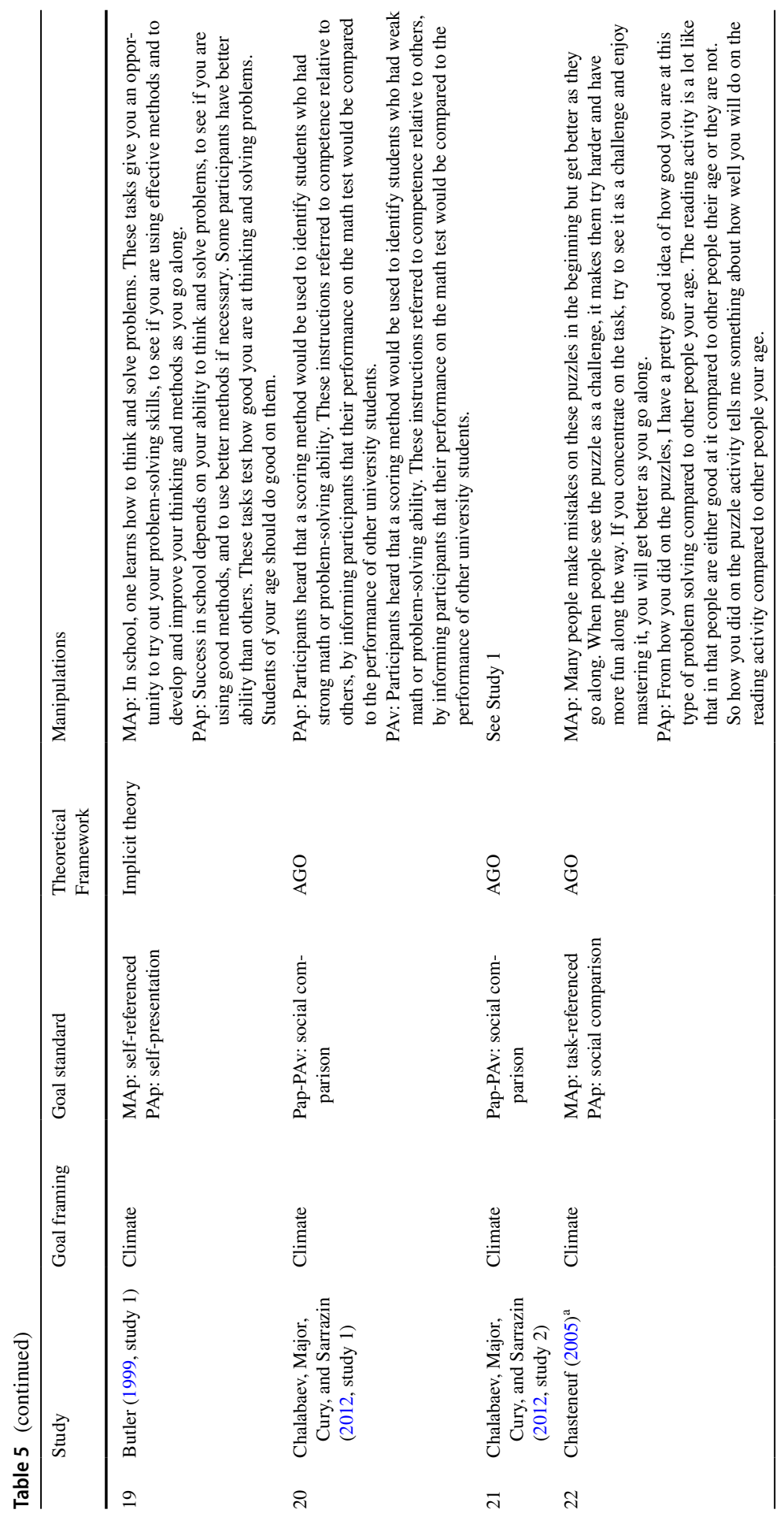




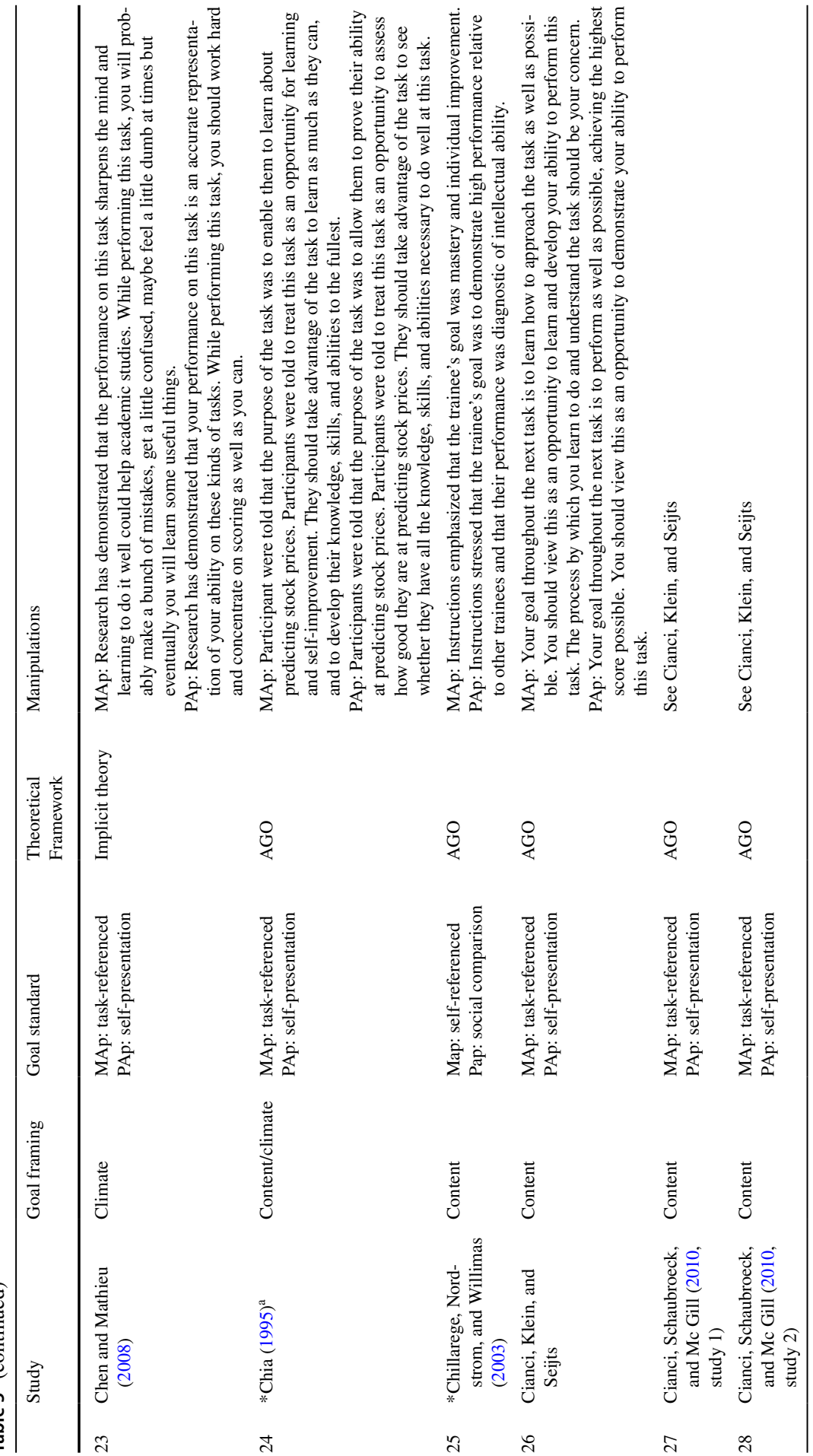




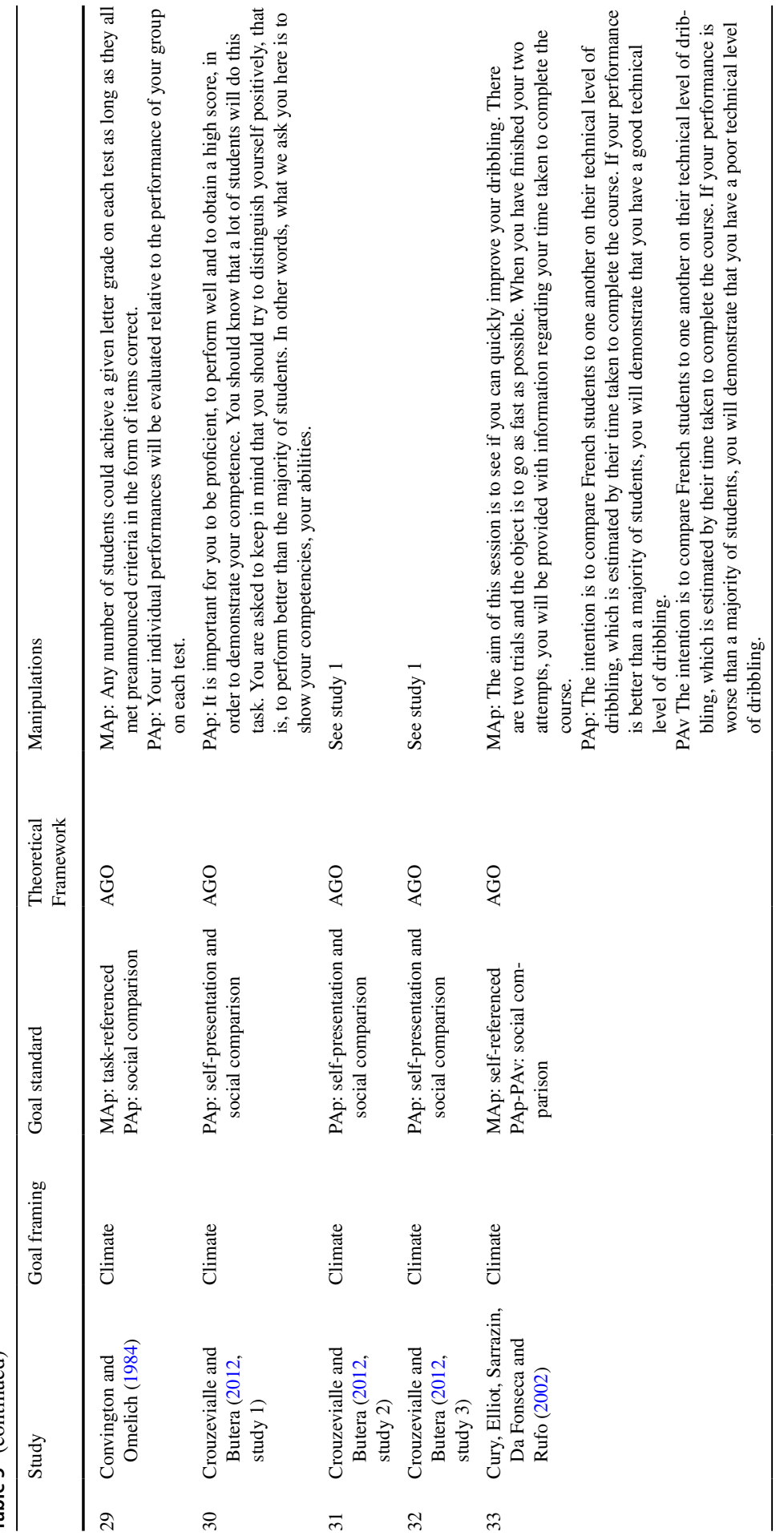




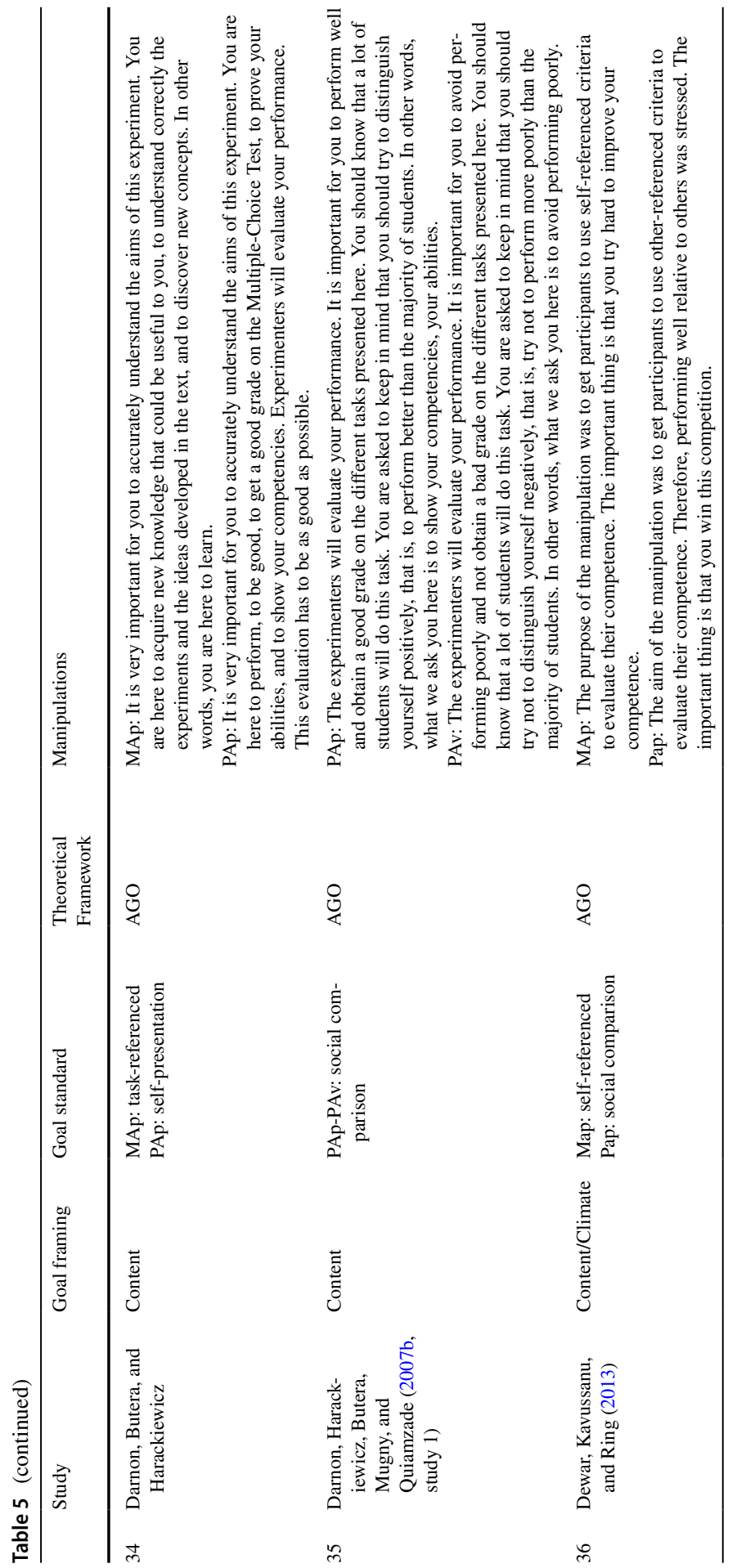




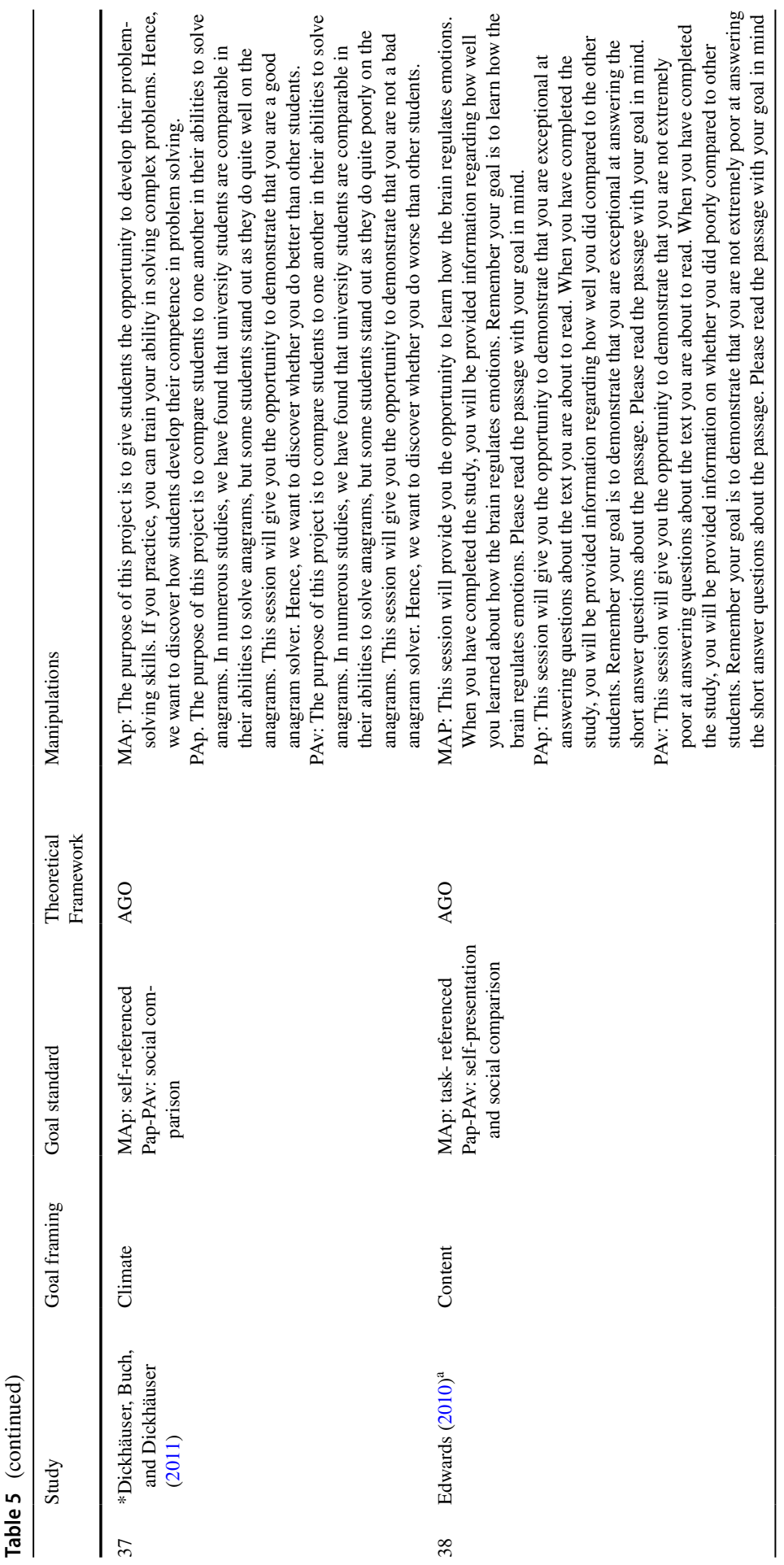




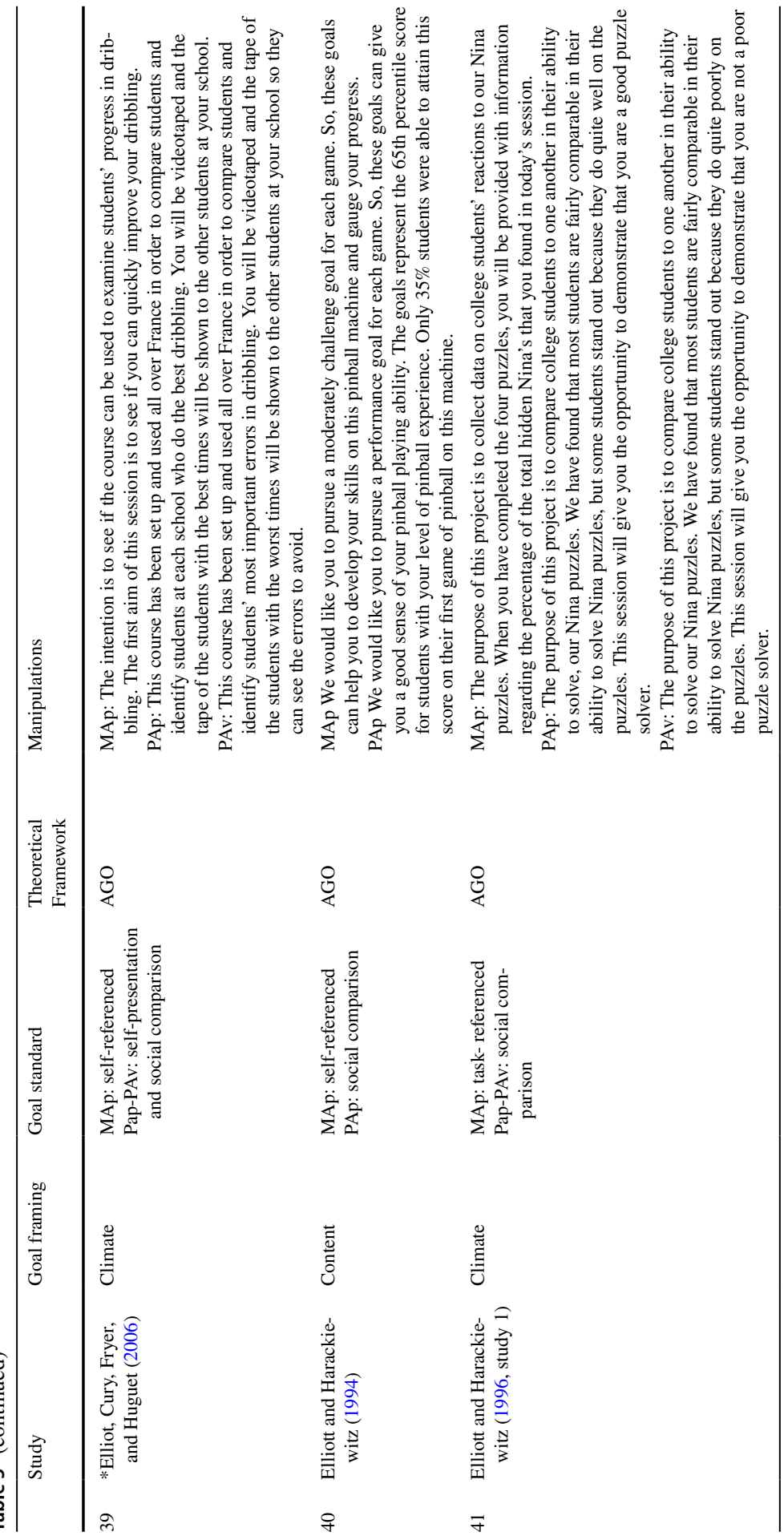




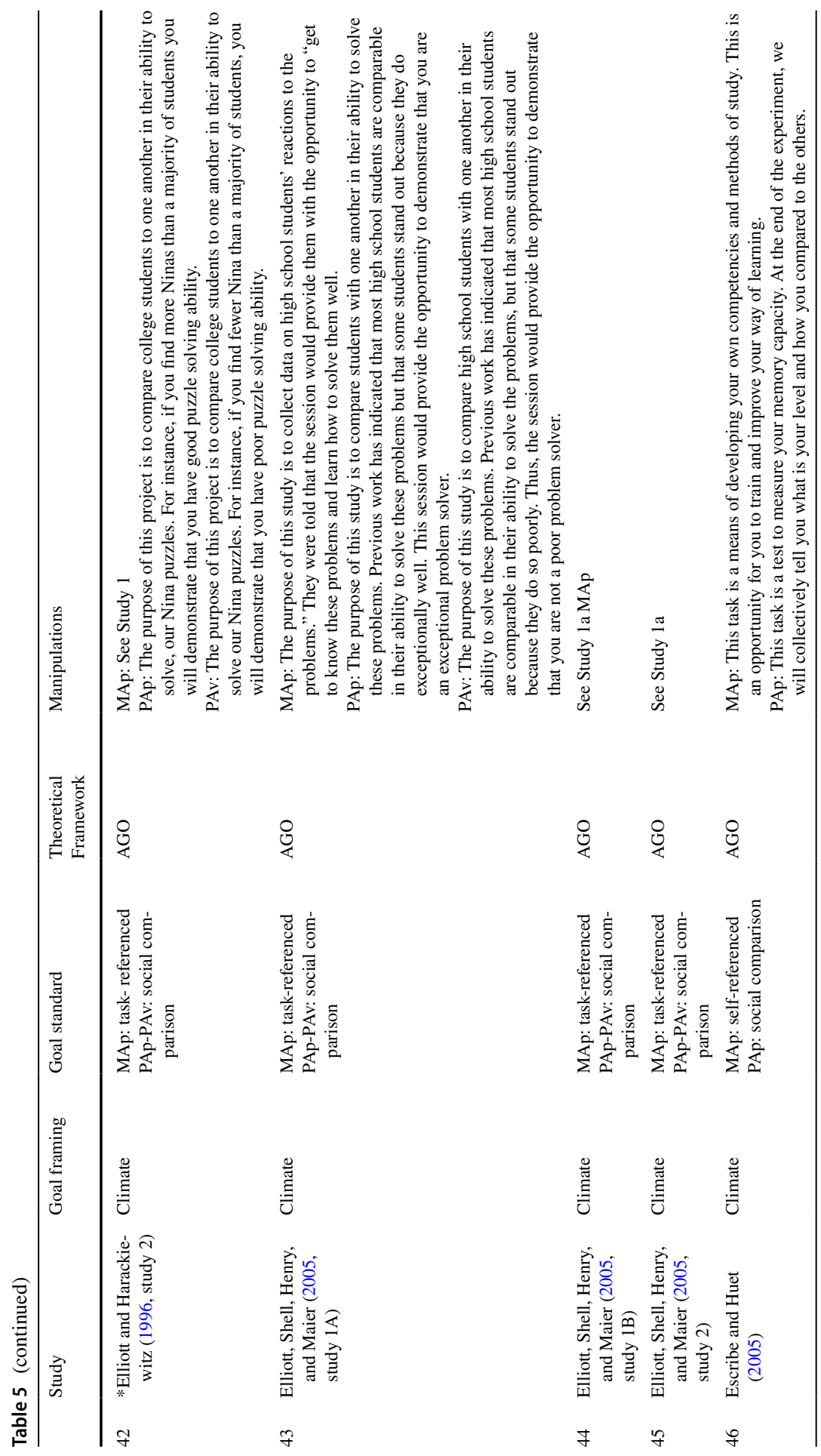




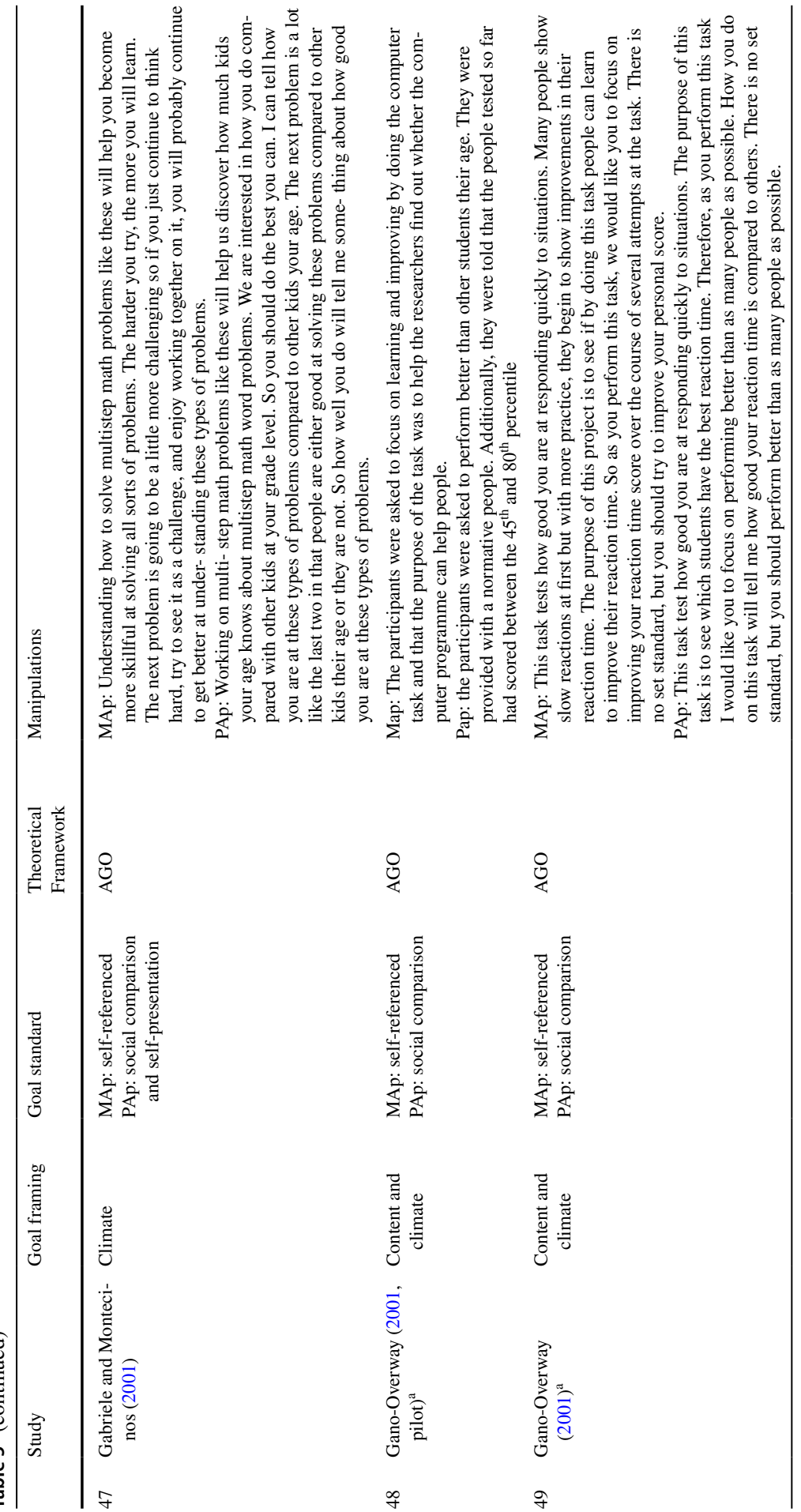




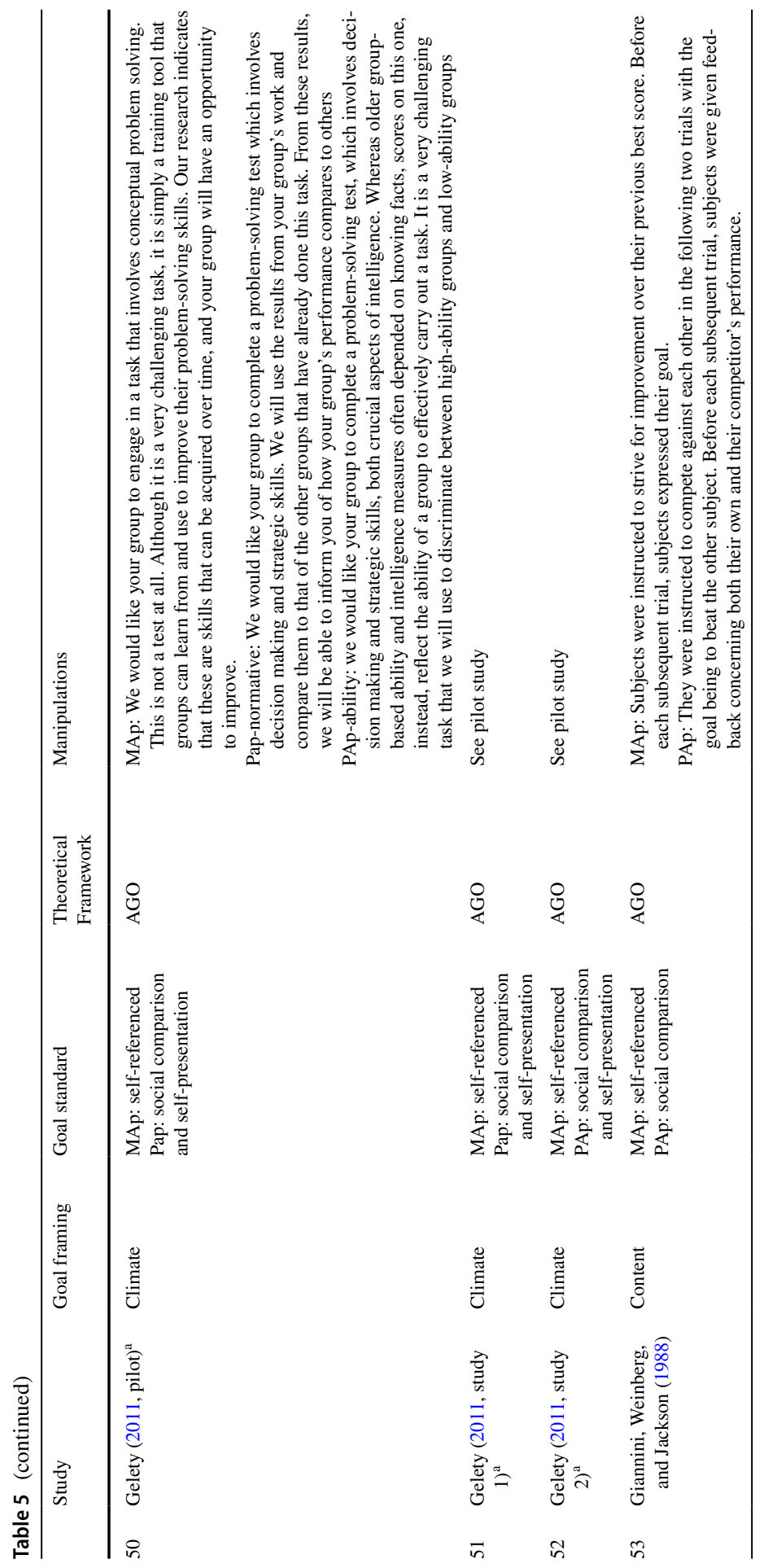




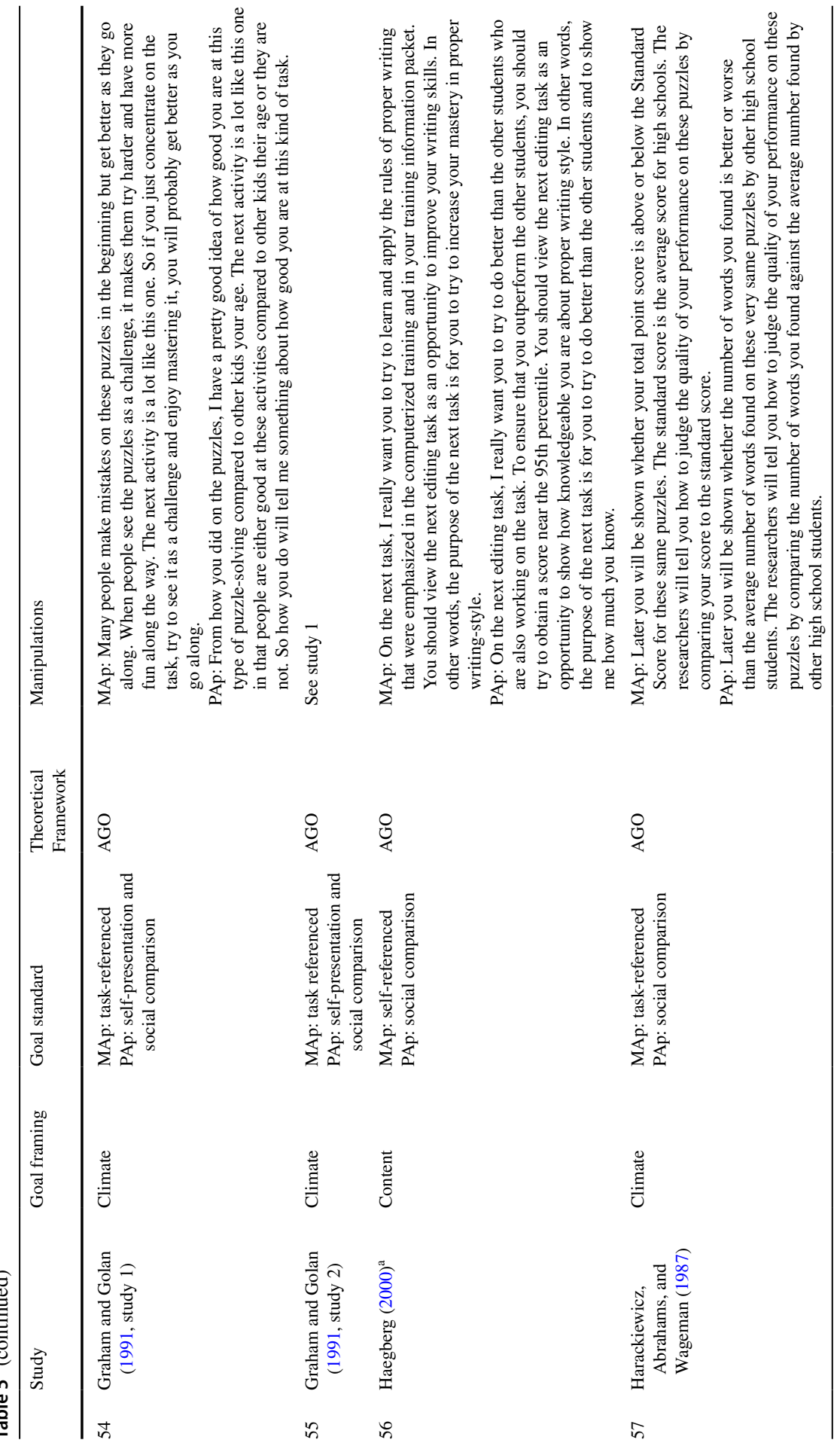




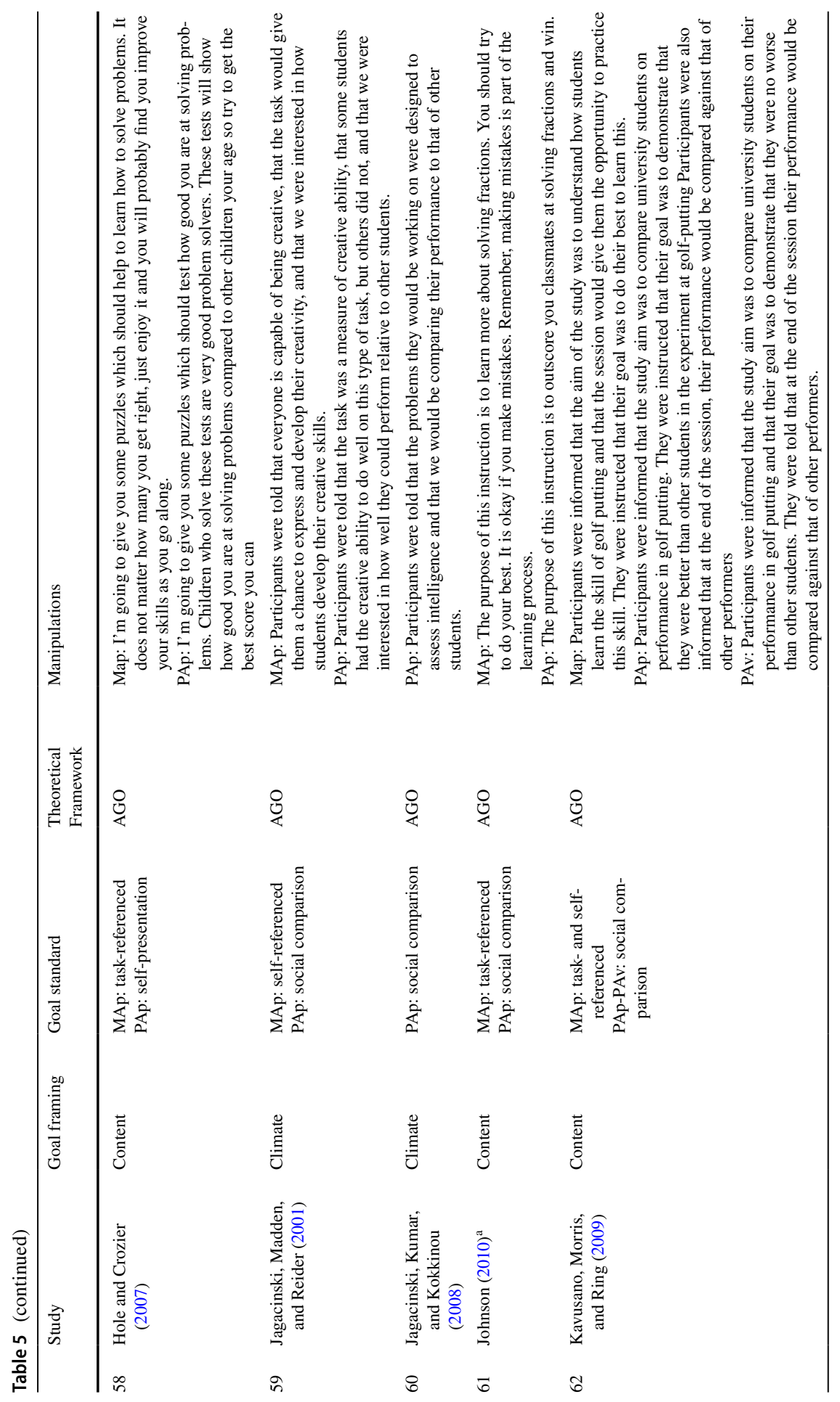




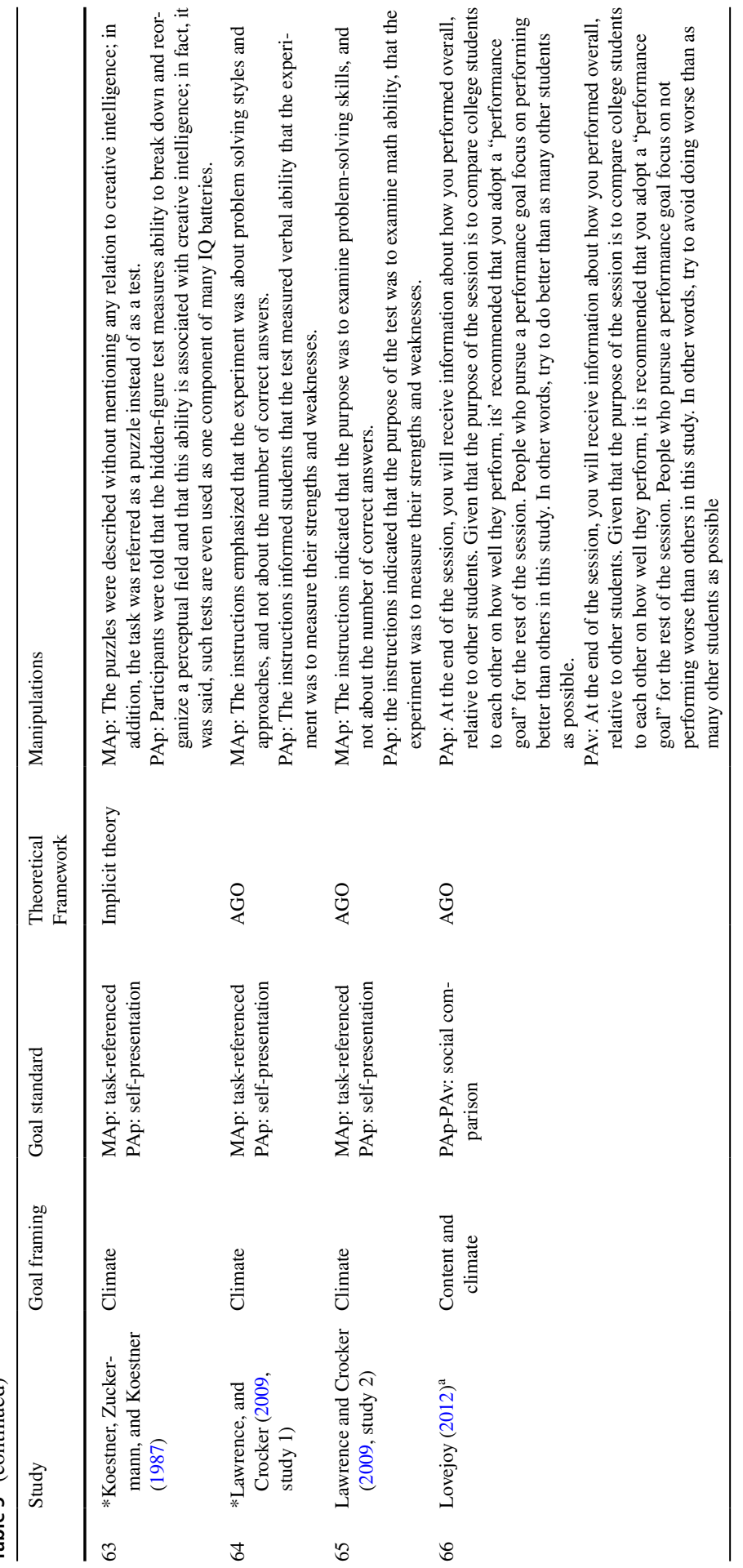




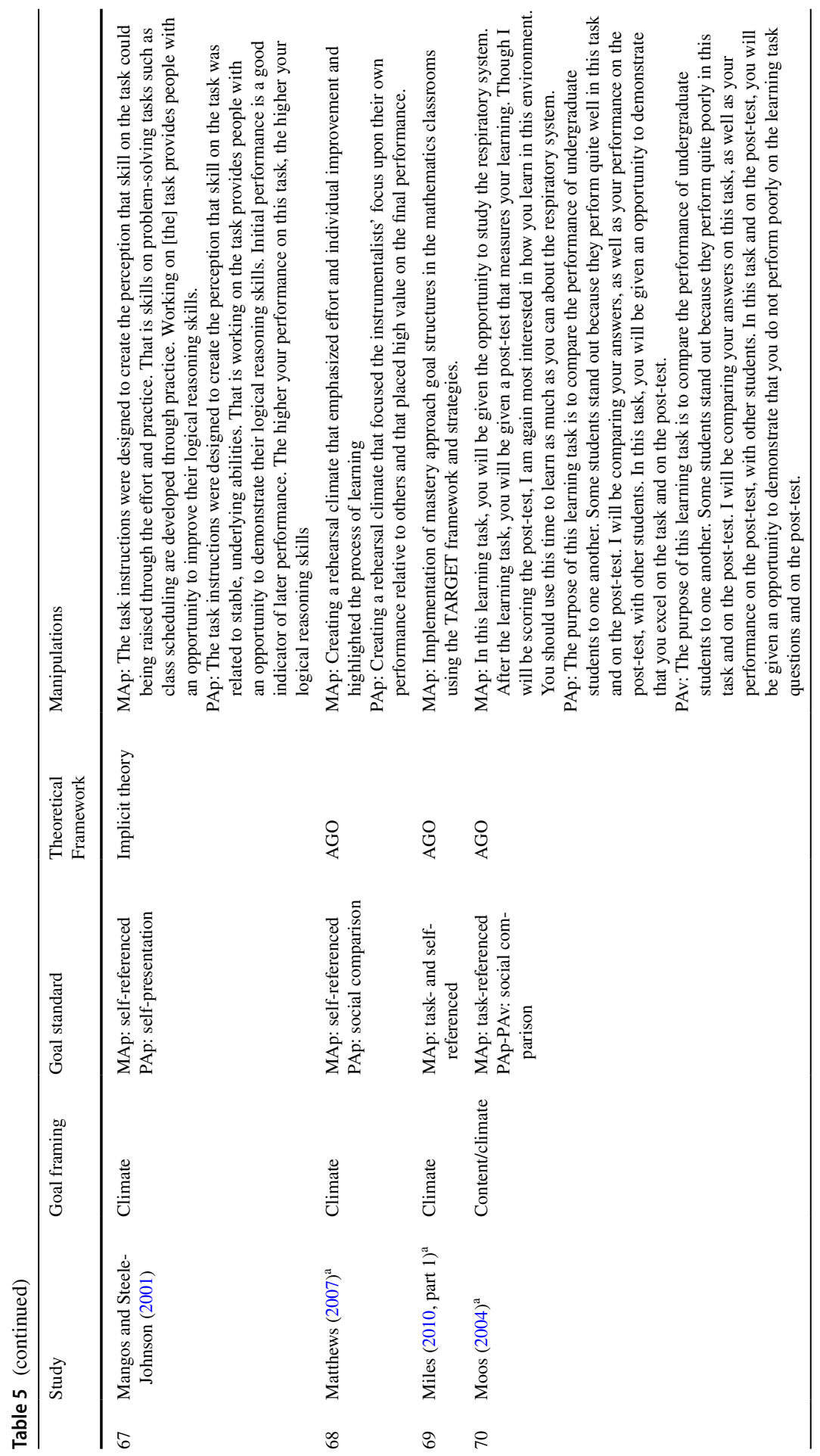




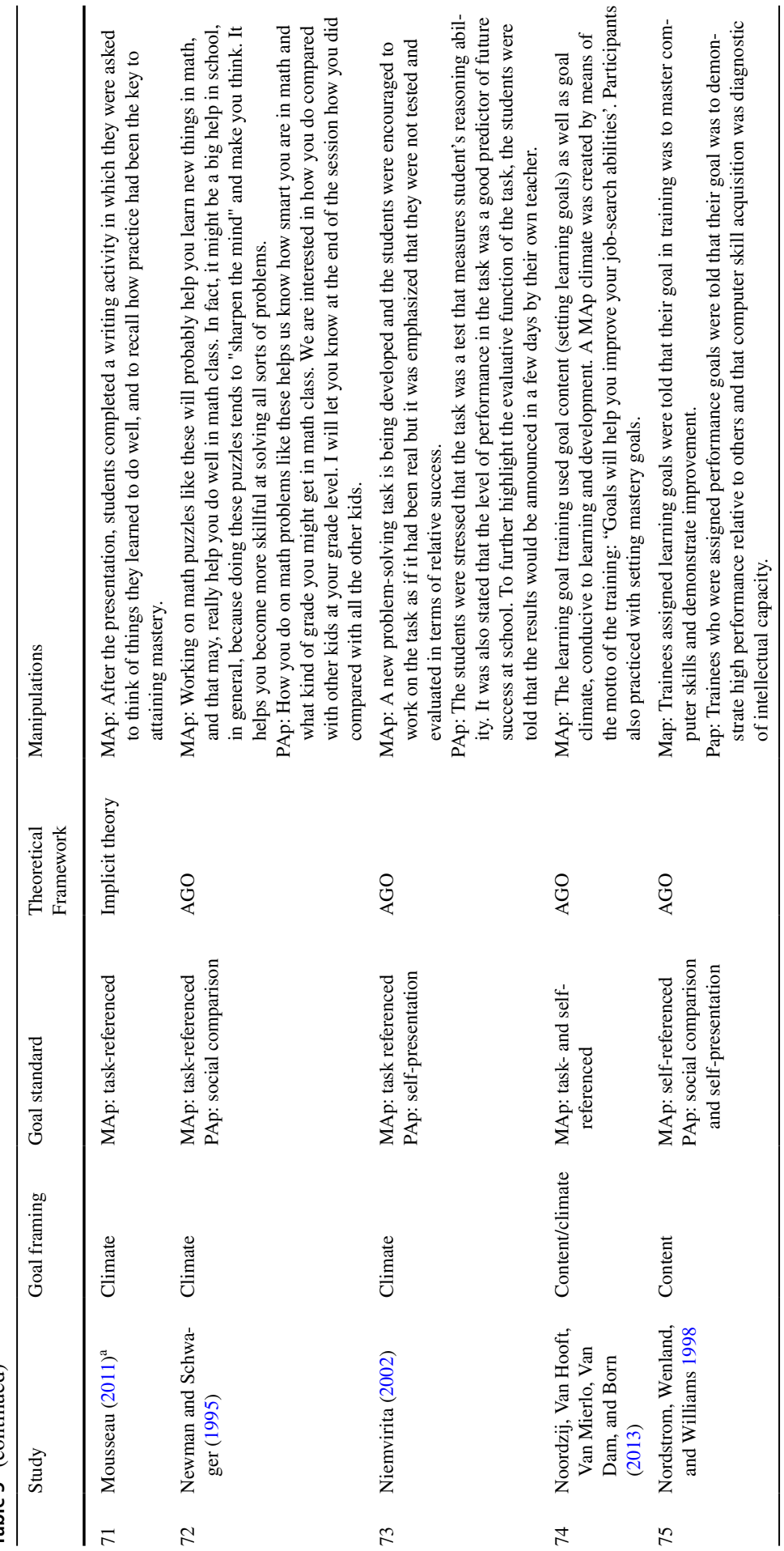




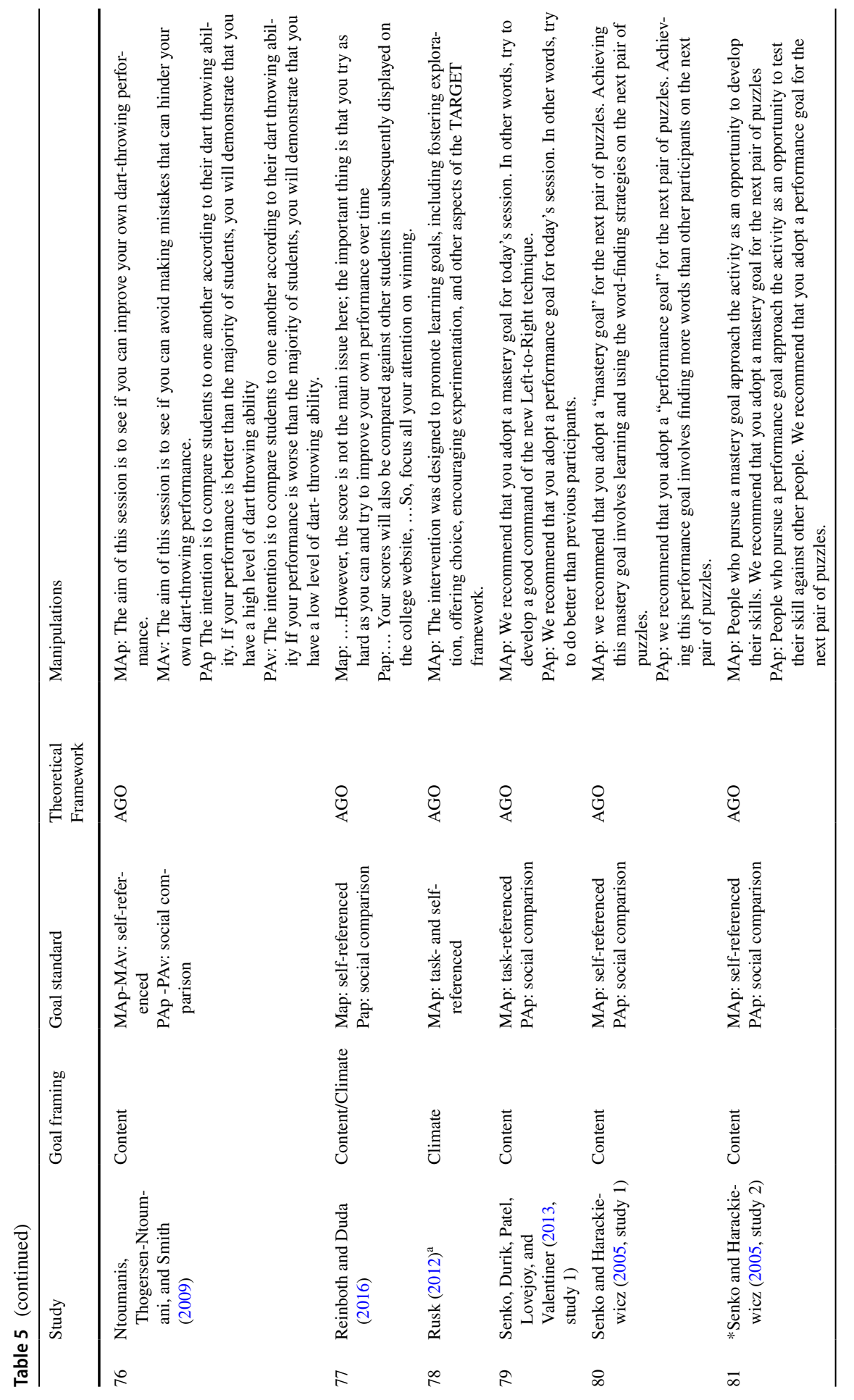




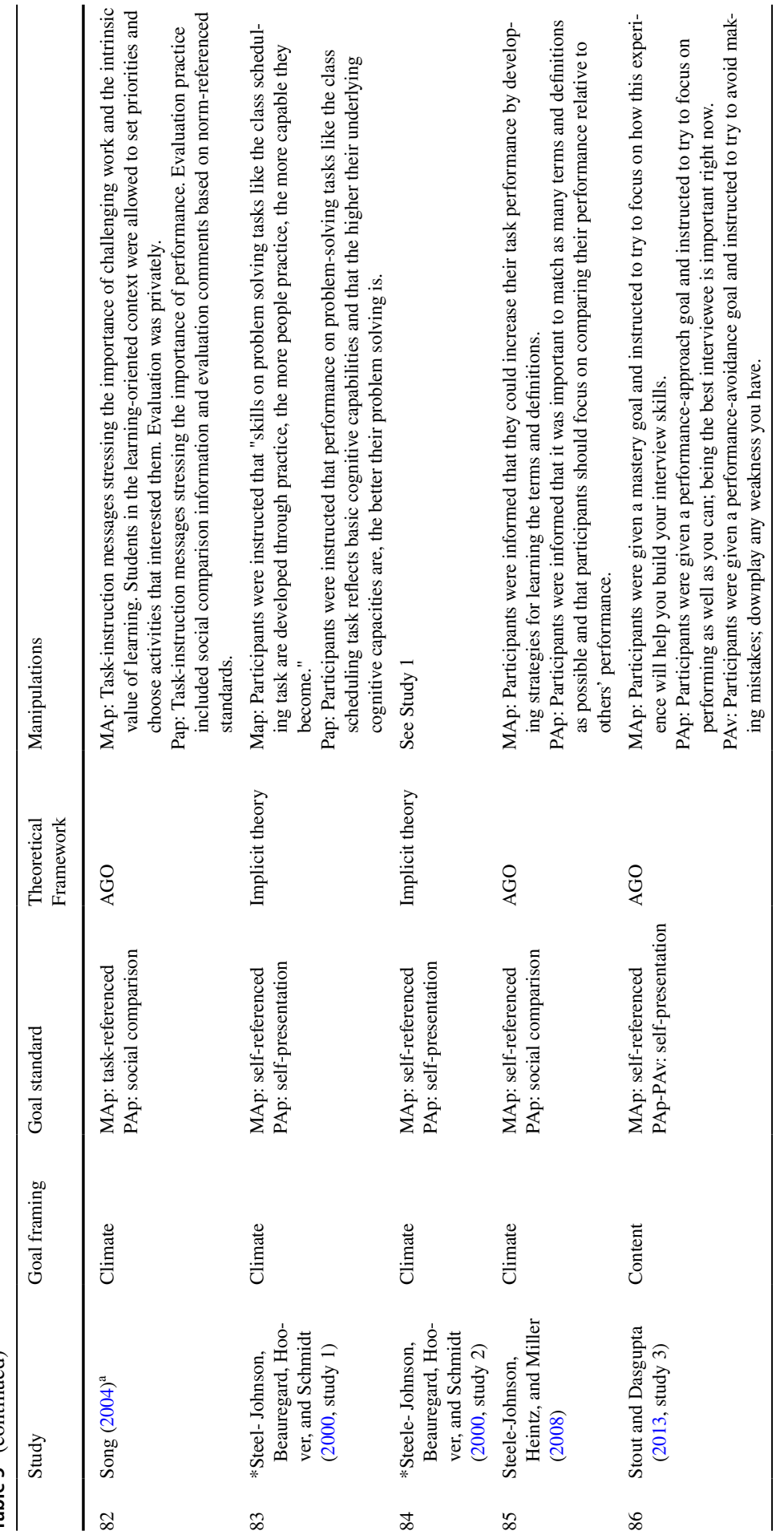




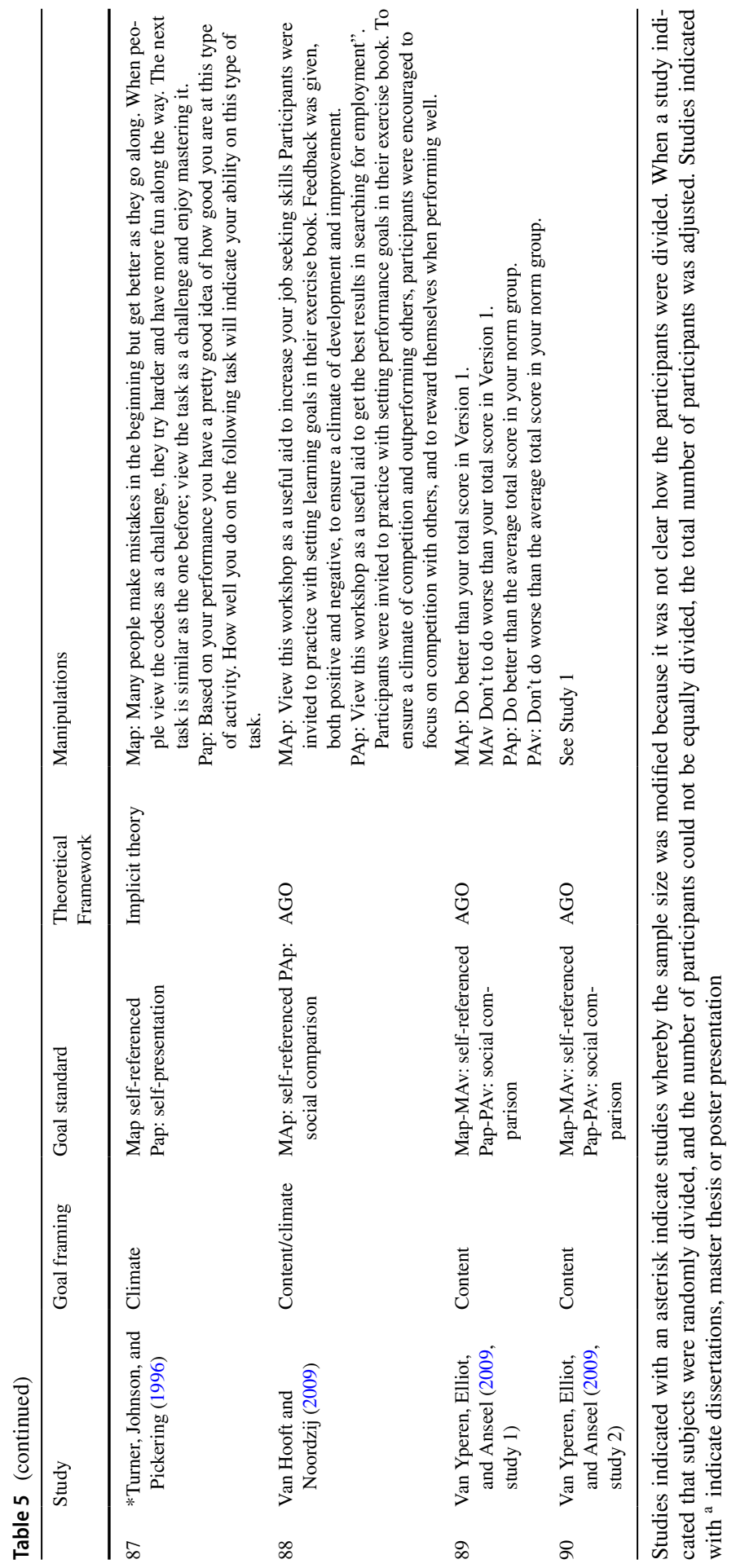




\subsection{Direct effects}

Our findings support our central tenet that, overall, induced mastery-approach goals result in higher task performance compared to performance-approach, performance-avoidance goals, and no-goal control conditions. This result is in line with the original assumptions of the achievement goal theory (e.g., Dweck and Leggett 1988; Nicholls 1984) and confirms the results of previous meta-analyses on induced achievement goals (e.g., Van Yperen et al. 2015). However, the results contradicts the findings of some previous meta-analyses that were correlational in nature (e.g., Hulleman et al. 2011). So, it seems that the two methodologies (i.e., self-reported goals vs. experimentally induced goals) produce different effects.

Remarkably, we found no difference in task performance between induced performance-approach and performance-avoidance goals. This result does not align with the common observation that performance-approach goals have beneficial effects, while performance-avoidance goals have detrimental effects on task performance (e.g., Elliot and Harackiewicz 1996; Senko et al. 2011), even when those goals are induced (Van Yperen et al. 2015). Our results for motivation, did, however, support the idea that induced performance-approach goals are more beneficial compared to performance-avoidance goals, but only for self-reported motivation and not for free-choice persistence. The question, then, is why this advantage of performanceapproach over performance-avoidance goals in terms of self-reported motivation did not translate into more motivated behavior (i.e., free-choice persistence) and/ or a performance benefit. Most studies inducing performance-avoidance goals were conducted in a lab setting. In this context, the most salient characteristics of performance-avoidance goals might be less prevalent. For example, opportunities for selfhandicapping are limited in lab settings and withdrawal is often almost impossible. In such a situation, where 'escape' or actual task avoidance is not an option, the aim of avoiding doing worse than others may motivate individuals to initiate action and strive for a performance level that prevents losing face (see also Van Mierlo and Van Hooft 2015). This striving to prevent losing face springs from an avoidance motive, which is likely reflected in the difference in self-reported motivation between performance-approach and performance-avoidance goals but not in actual motivated behavior or performance level.

\subsection{Moderating effect of goal standard}

As proposed by both Elliot et al. (2011) and Hulleman et al. (2011), processing and pursuing a task-referenced mastery goal requires fewer cognitive resources than processing and pursuing a self-referenced mastery goal. Previous correlational research based on self-reported achievement goals (e.g., Elliot et al. 2011) indeed shows a performance advantage for mastery-approach goals with a task-referenced goal standard compared to a self-referenced standard. Our findings support this notion by showing that the inducement of mastery-approach goals based on a task-referenced goal standard for evaluation (i.e., learning and mastering a task), translates in a performance gain for those goals compared to performance-approach goals. 
An example of a task-referenced standard for mastery-approach goal manipulations is the following: "This session will provide you with the opportunity to learn how to solve the problems well" (Bjørnebekk, Gsjeme, and Ulrikson 2011, p. 361). Evaluation of goal achievement based on this manipulation requires that participants cognitively represent the problem-solving task and determine their level of accomplishment. The frame of reference for evaluation is the task itself and participants' attention likely remains task-focused, which requires only limited cognitive resources (Elliot et al. 2011).

In contrast to a task-based standard for evaluation, when performance is evaluated in terms of intrapersonal criteria (e.g., doing better than one did before), the inducement of mastery-approach goals translates into a performance gain for masteryapproach goals compared to performance-approach goals. Consider, for example, the mastery-approach goal manipulation "Do better than your total score in Version 1 ", used by Van Yperen and colleagues (2009, p. 935). Evaluation of goal achievement based on this manipulation requires that participants cognitively represent and compare two outcomes at the same time (i.e., Version 1 versus Version II). Moreover, in case of self-referenced standards, the frame of reference for evaluation is more self-based and less task-based, which may cause participants' attention to shift from the task itself towards maintaining a positive self-concept (Elliot et al. 2011).

The performance advantage of mastery-approach goals over performanceapproach goals also depended on the goal standard that was used to induce performance-approach goals. Previous correlational research (Hulleman et al. 2010; Senko and Dawson 2017) suggests a performance benefit of social-comparison over selfpresentation (i.e., appearances) standards for performance-approach goals. This should translate into a performance benefit for mastery-approach goals when performance-approach goals are induced via self-presentation standards. In our meta-analysis, however, we only found a significant performance benefit for mastery-approach goals when performance-approach goals were induced via social-comparison standards. Some caution is due when interpreting these results because of the small difference between the confidence intervals for social comparison (0.05-0.46) and self-presentation (-0.03-0.30). Despite being cautious about this result, it still raises the question whether there might be a difference between self-reported and manipulated performance-approach goals with regards to the standard of evaluation that is utilized.

Already in the eighties of the past century, Dweck (1986) and Convington (1984) argued that performance goals are closely related to self-worth. Following this line of reasoning and focusing on self-reported achievement goals, Hulleman and colleagues (2010) argued and demonstrated that self-presentation performanceapproach goals are more closely tied to one's self-worth compared to social comparison performance-approach goals. Our results suggest that this difference between self-presentation and social comparison standards of evaluation disappears and may even reverse when performance-approach goals are induced rather than measured with self-reports. Several reasons might explain why, in an experimental setting, a self-presentation standard of evaluation is less tied to one's self-worth and therefore less likely to result in adverse effects for performance-approach goals relative to mastery-approach goals. First, self-presentation manipulations are often aimed at 
a specific skill or ability (e.g., logical reasoning skills). They do not address broader self-evaluative constructs such as being 'smart' or 'good', as do items measuring self-presentation performance-approach goals in self-report studies (e.g., "It is important that others know that I'm a good student"; VandeWalle 1997a, b). Such broad conceptions of demonstrating ability that are, moreover, self-imposed (i.e., measured rather than induced), present a much stronger ego-threat compared to narrowly defined skills that may have limited personal relevance outside the experimental setting. Second, self-presentation manipulations rarely involve a 'real' or meaningful audience or target person, even though they are sometimes framed in relation to the experiment leader. In self-report studies, however, the target person(s) to whom one seeks to demonstrate one's ability is or are self-selected and salient and, hence, likely to be more meaningful. Without significant others present, an induced performance-approach goal based on a self-presentation standard seems less tied to one's self-worth. However, in case of social comparison standards of evaluation, this same lack of significant others may be detrimental for performance. In the experimental settings in our meta-analysis, social comparison was mostly manipulated via aggregated normative scores that were often unknown to the participants until after task completion (e.g., 'The computer will give you feedback about how well you did compared to others'; Bodman 2008, p. 87). In case of aggregated scores, participants are unable to judge whether they perform better than others during task performance. Those feelings of uncertainty may prompt a slacking of effort and heightened fear of failure (cf., Dweck and Leggett 1988). In contrast, when performance-approach goals are self-reported, the comparison others are specific and selfselected and most of the time known (e.g., "My goal in this class is to do better than others"; item from Elliot and McGregor 2001). In such contexts, when the comparison others are known, individuals are better able to judge whether their goal of outperforming others is feasible, and whether they are on track to achieve their goal. Another explanation might be the different reasons for social comparison. According to Senko and Tropiano (2016) the goal of outperforming others can be based on controlled or autonomous reasons. The first one resulting in maladaptive effects and the last one resulting in adaptive results. One can argue that the inducement of a performance goal with the instruction of outperforming others will likely result in individuals who has a controlled reason to strive for this goal.

In all, the different standards of evaluation partly explain the performance differences between mastery-approach goals and performance-approach goals in experimental settings. It is important to note that no studies in our sample included a direct comparison of different goal standards. As such, our findings do not allow us to compare the performance effects of task-referenced mastery-approach goals to those of self-referenced mastery-approach goals or for social-comparison performanceapproach goals to those of self-presentation performance-approach goals. We can only conclude that whether or not there was a significant difference in performance between induced mastery-approach and performance-approach goals depended on the different standards of evaluation that were used. 


\subsection{Moderating effect of goal framing}

Our findings for goal framing support Kozlowski and Bell's (2006) proposition that the exact framing of achievement goal interventions matters. Induced masteryapproach goals only showed performance benefits relative to induced performanceapproach goals when goal content was manipulated. No such benefit was found for manipulations that only focused on goal climate. This finding indicates that there is no difference in performance between induced mastery-approach or performanceapproach goals unless participants are assigned, or instructed to adopt, specific goals for an upcoming task (e.g., "Your goal whilst performing this memory task is to detect as many correct number matches as you can in order to perform better than other students taking part"; Avery and Smilie 2013, p. 42.)

Although our findings might appear to support the idea of goal content manipulation as superior to goal climate manipulation, we would like to call for caution when drawing conclusions about the role of goal framing based on studies on induced achievement goals. As Kozlowski and Bell (2006) argued, goal content manipulations shape self-regulation and action more directly than goal climate manipulations resulting in a stronger immediate effect. Goal climate manipulations take more time to materialize because they affect self-regulatory processes that generate effects mainly in the longer term. This postponed effect can result in a relatively weak but more durable effects of goal climate manipulations. Most studies on induced achievement goals focus on immediate, short-term outcomes, so that potential goal climate effects may remain undetected. The few studies measuring long-term outcomes did demonstrate positive effects for the inducement of a mastery-approach goal climate compared to a performance-approach climate (Convington and Omelich 1984; Miles 2010). Furthermore, research on classroom structure and teacher pedagogical style indicates that in general a mastery-approach climate leads to the most optimal learning outcomes (e.g., Murayama and Elliot 2009). However, for the time being, these are speculative reflections, also because the studies in our sample did not explicitly differentiate between different types of goal framing. Based on our results, we strongly recommend that future studies differentiate between goal content and goal climate operationalizations and examine potential differences in effects over time and across different outcomes.

\subsection{Additional moderators}

Mastery-approach goals were more beneficial for performance than performanceapproach goals when the manipulation was based on the $2 \times 2$ achievement goal theory (Elliot and McGregor 2001), but not when the manipulation was based on the implicit theories of ability (Dweck 1986). Dweck theorized that implicit theories of ability serve as antecedents of achievement goals: Believing that abilities can be improved likely results in the adoption of mastery goals, whereas believing that abilities are fixed likely results in the adoption of performance goals. Previous metaanalyses (Burnette, O'Boyle, VanEpps, Pollack, and Finkel 2013; Payne et al. 2007) indeed found an association between implicit theories of ability and achievement 
goals. However, the correlations were rather weak. Furthermore, as argued by Dweck (2000), implicit theories influence self-regulatory processes which, in turn, predict achievement. Dweck therefore proposes that implicit theories only have a weak direct effect on achievement. As such, in our meta-analysis, the achievement goal manipulations based on the incremental theories of ability might not have been powerful enough to trigger performance differences between induced masteryapproach and performance-approach goals. Manipulations based on the incremental theory can certainly be relevant in their own right (see Sisk, Burgoyne, Sun, Butler, and McNamara 2018), but the incremental theory seems less suitable as underlying framework for the manipulation of achievement goals. The performance difference between induced mastery-approach and performance-approach goals only emerged in the lab, and not in the other domains (educational, sports, or work). The non-significant results for the other domains might be due to the relatively small numbers of studies conducted in the educational (11), sport (7), and work (2) domain compared to the lab (47). More specific, the effect sizes for education and sport almost reached significance. As such, future research should examine the effects of induced achievement goals in the different fields to investigate whether this performance difference between induced mastery-approach and performance-approach goals also emerges in the "real world" and not only in the lab.

Mastery-approach goals were also more beneficial when participants were older than 18 years but not when they were below 18 years of age. This latter finding is in line with Nicholls (1978), who proposed that children's' conception of ability changes around the age of 12, when they start to distinguish between effort (related to mastery goals) and ability (related to performance goals). However, it seems that for the inducement of achievement goals children hardly differentiate between mastery and performance goals and only when they reach adulthood their ability to distinguish between mastery-approach and performance-approach goals becomes prominent. Finally, the difference between induced mastery-approach and performance-approach goals was not affected by gender.

\subsection{Limitations and considerations for future research}

Although we established a robust positive effect of induced mastery-approach goals on performance relative to performance-approach, performance-avoidance goals, and no-goals, more research is needed to allow comprehensive tests of all possible contrasts in relation to motivation as well as performance. Studies on induced mastery-avoidance goals are particularly scarce. In addition, we did not include the effects of manipulated multiple goals on different outcomes (see for example, Linnenbrink 2005; Pahljina-Reinić and Kolić-Vehovec 2017).

Furthermore, due to sample size limitations, we could only test for moderators in the contrast between mastery-approach and performance-approach effects, and only for effects on task performance. In addition, we examined the effects of each moderator separately, as the sample size was not sufficient for nested moderation analyses. Moreover, the heterogeneity in effect sizes was not fully accounted for by our moderators. Additional potential moderators of the performance effects of induced state 
achievement goal might include task complexity (see Utman 1997), task demands (see Steele-Johnson, Beauregard, Hoover, and Schmidt 2000), or feedback and time pressure (Van Yperen et al. 2015).

Another issue that should be addressed in future studies concerns the inclusion of manipulation checks and control conditions. Not all studies in our meta-analysis included a manipulation check and/or a control condition. A manipulation check is essential to ensure that effects can indeed be attributed to the intended change in achievement goals. Investigating the differential effects of induced achievement goals can be done without a control group but this does not allow for conclusions about the effects of achievement goals compared to the absence of such goals. Thirty-six out of the 90 studies included a control condition, and the nature of those control conditions differed dramatically. Some control conditions only comprised a short general task or 'do you best' instruction (e.g., Darnon, Harackiewicz, Butera, Mugny, and Qiumzade 2007), while other control conditions had the same structure as the experimental conditions (e.g., Noordzij, Van Hooft, Van Mierlo, Van Dam, and Born 2013). Although all these conditions still qualify as control conditions in the sense that they involved no explicit achievement goal manipulations, results for the control group contrasts are difficult to interpret because of the heterogeneity within this category. We recommend that future studies include manipulation checks and control conditions with the same structure as the experimental condition, as this would enhance methodological rigor and contribute to the validity of results for the inducement of achievement goals.

Finally, when designing and implementing achievement goal manipulations and interventions, we strongly recommend that future studies take the role of goal framing and goal standard into account. Educational researchers (e.g., Ames 1992) in the early nineties already suggested that mastery goals should be promoted in school policies and teacher education programs. Those early researchers did not take into account that mastery goals could be phrased by referring to mastering a task or to improve oneself compared to previous accomplishments (i.e., goal standard) or could be induced by means of content or climate (i.e., goal framing). The same holds for the studies included in this meta-analysis; none of them explicitly named the goal standard or the goal framing. So, at the very least we argue that a new gold standard for future research should be to explicitly report what goal standard was used and how goals were framed (see for an example, Chung, Bong, and Kim 2019). Our coding procedure and outcomes for these moderators indicate that increasing clarity on these issues is indeed warranted. With regards to goal framing, examining both the short-and long-term effects of achievement goal content and goal climate manipulations could add to the understanding of the effects of achievement goal interventions.

\section{Conclusion and practical considerations}

Achievement goal theory is one of the most influential motivational theories of the last decades. Previous meta-analytical findings of the correlational research on selfreported achievement goals provided valuable information about the connection 
between achievement goals and motivation and performance across domains and contexts. However, when it comes to the practical implications of achievement goal theory, meta-analytical findings based on experimental research provide a more solid basis for the development of interventions aimed at enhancing motivation and performance in the educational, sports, and work domain. Practically speaking, mastery-approach goals are more beneficial for performance compared to other achievement goals. So, interventions should first and foremost induce mastery-approach goals by structuring task to convey students, athletes, and employees that learning and mastering something new involves making mistakes and requires effort. More specifically, teachers but also sports coaches, trainers, and employers should promote mastery-approach goals focusing on learning and mastering a task and less on comparing oneself to previous accomplishments or to others.

\section{Compliance with ethical standards}

Conflict of interest The authors declare that there is no conflict of interest.

Open Access This article is licensed under a Creative Commons Attribution 4.0 International License, which permits use, sharing, adaptation, distribution and reproduction in any medium or format, as long as you give appropriate credit to the original author(s) and the source, provide a link to the Creative Commons licence, and indicate if changes were made. The images or other third party material in this article are included in the article's Creative Commons licence, unless indicated otherwise in a credit line to the material. If material is not included in the article's Creative Commons licence and your intended use is not permitted by statutory regulation or exceeds the permitted use, you will need to obtain permission directly from the copyright holder. To view a copy of this licence, visit http://creativecommons.org/licen ses/by/4.0/.

\section{References}

\section{References marked with an asterisk indicate studies included in the meta-analysis.}

Ames, C. (1992). Classrooms: Goals, structures, and student motivation. Journal of Educational Psychology, 84, 261-271.

*Anseel, F., Van Yperen, N. W., Janssen, O., \& Duyck, W. (2011). Feedback type as a moderator of the relationship between achievement goals and feedback reactions. Journal of Occupational and Organizational Psychology, 84, 703-722. https://doi.org/10.1348/096317910X516372.

*Avery, R. E., \& Smillie, L. D. (2013). The impact of achievement goal states on working memory. Motivation and Emotion, 37, 39-49. https://doi.org/10.1007/s11031-012-9287-4.

Baranik, L. E., Stanley, L. J., Bynum, B. H., \& Lance, C. E. (2010). Examining the construct validity of mastery-avoidance achievement goals: A meta-analysis. Human Performance, 23, 265-282. https ://doi.org/10.1080/08959285.2010.488463.

Bardach, L., Yanagida, T., Klassen, R. M., \& Lüftenegger, M. (2020). Normative and appearance performance-approach goal structures: Two-level factor structure and external linkages. The Journal of Experimental Education. https://doi.org/10.1080/00220973.2020.1729081.

*Barker, K. L., McInerney, D. M., \& Dowson, M. D. (2002). Performance approach, performance avoidance and depth of information processing: A fresh look at relations between students' academic motivation and cognition. Educational Psychology, 22, 571-589. https://doi.org/10.1080/01443 41022000023644 . 
*Barkoukis, V., Tsorbatzoudis, H., \& Grouios, G. (2008). Manipulation of motivational climate in physical education: Effects of a seven-month intervention. European Physical Education Review, 14, 367-387. https://doi.org/10.1177/1356336X08095671.

*Barron, K. E., \& Harackiewicz, J. M. (2001). Achievement goals and optimal motivation: Testing multiple goal models. Journal of Personality and Social Psychology, 80, 706. https://doi. org/10.1037/0022-3514.80.5.706.

*Bereby-Meyer, Y., \& Kaplan, A. (2005). Motivational influences on transfer of problem-solving strategies. Contemporary Educational Psychology, 30, 1-22. https://doi.org/10.1016/j.cedps ych.2004.06.003.

*Bergin, D. A. (1995). Effects of a mastery versus competitive motivation situation on learning. The Journal of Experimental Education, 63, 303-314. https://doi.org/10.1080/00220973.1995.99434 66.

Biddle, S., Wang, C. J., Kavussanu, M., \& Spray, C. (2003). Correlates of achievement goal orientations in physical activity: A systematic review of research. European Journal of Sport Science, 3, 1-20. https://doi.org/10.1080/1750984X.2010.548528.

*Bjernebekk, G., Gjesme, T., \& Ulriksen, R. (2011). Achievement motives and emotional processes in children during problem-solving: Two experimental studies of their relation to performance in different achievement goal conditions. Motivation and Emotion, 35, 351-367. https://doi.org/10.1007/ s11031-011-9224-y.

*Blaga, M., Van Yperen, N. (2011, January). Yes, I can. Performance expectancy moderates the link between easy and difficult achievement goals and performance. Poster presented at the annual meeting of the Society for Personality and Social Psychology, San Antonio, TX.

*Bodmann, S. M. (2008). Achievement goal systems: Implications for research and educational policy (Doctoral dissertation). Madison, WI: University of Wisconsin.

Bong, M. (2009). Age-related differences in achievement goal differentiation. Journal of Educational Psychology, 101(4), 879-896. https://doi.org/10.1037/a0015945.

Borenstein, M., Hedges, L., Higgins, J., \& Rothstein, H. (2005). Comprehensive meta-analysis (Version 2) [Computer software]. Englewood, NJ: Biostat.

Borenstein, M., Hedges, L., Higgins, J., \& Rothstein, H. (2009). Introduction to meta-analysis. New York: John Wiley.

*Bouffard, T., Bouchard, M., Goulet, G., Denoncourt, I., \& Couture, N. (2005). Influence of achievement goals and self-efficacy on students' self-regulation and performance. International Journal of Psychology, 40, 373-384. https://doi.org/10.1080/00207590444000302.

Burnette, J. L., O’Boyle, E. H., VanEpps, E. M., Pollack, J. M., \& Finkel, E. J. (2013). Mind-sets matter: A meta-analytic review of implicit theories and self-regulation. Psychological Bulletin, 139, 655-701. https://doi.org/10.1037/a0029531.

*Butler, R. (1992). What young people want to know when: Effects of mastery and ability goals on interest in different kinds of social comparisons. Journal of Personality and Social Psychology, 62, 934-943. https://doi.org/10.1111/j.2044-8279.1988.tb00874.x.

*Butler, R. (1993). Effects of task-and ego-achievement goals on information seeking during task engagement. Journal of Personality and Social Psychology, 65, 18-31. https://doi. org/10.1037//0022-3514.65.1.18.

*Butler, R. (1995). Motivational and informational functions and consequences of children's attention to peers' work. Journal of Educational Psychology, 87, 347-360. https://doi. org/10.1037//0022-0663.87.3.347.

*Butler, R. (1999). Information seeking and achievement motivation in middle childhood and adolescence: The role of conceptions of ability. Developmental Psychology, 35, 146-163. https://doi. org/10.1037//0012-1649.35.1.146.

Button, S. B., Mathieu, J. E., \& Zajonc, D. M. (1996). Goal orientation in organizational research: A conceptual and empirical foundation. Organizational Behavior and Human Decision Processes, 67, 26-48. https://doi.org/10.1006/obhd.1996.0063.

Cellar, D. F., Stuhlmacher, A. F., Young, S. K., Fisher, D. M., Adair, C. K., Haynes, S., \& Riester, D. (2011). Trait goal orientation, self-regulation, and performance: A meta-analysis. Journal of Business and Psychology, 26, 467-483. https://doi.org/10.1007/s10869-010-9201-6.

*Chalabaev, A., Major, B., Sarrazin, P., \& Cury, F. (2012). When avoiding failure improves performance: Stereotype threat and the impact of performance goals. Motivation and Emotion, 36, 130-142. https://doi.org/10.1007/s11031-011-9241-X. 
*Chasteauneuf, C. A. (2004). The role of goal orientations in text-based learning (Doctoral dissertation). Ottawa, Canada: University of Victoria.

*Chen, G., \& Mathieu, J. E. (2008). Goal orientation dispositions and performance trajectories: The roles of supplementary and complementary situational inducements. Organizational Behavior and Human Decision Processes, 106, 21-38. https://doi.org/10.1016/j.obhdp.2007.11.001.

*Chia, B. (1995). The effects of assigned goals on goal orientation, learning, and performance in a new and complex task (Doctoral dissertation). Singapore: The University of British Columbia.

*Chillarege, K. A., Nordstrom, C. R., \& Williams, K. B. (2003). Learning from our mistakes: Error management training for mature learners. Journal of Business and Psychology, 17, 369-385. https:// doi.org/10.1023/A:1022864324988.25.

Chung, Y., Bong, M., \& Kim, S. I. (2019). Performing under challenge: The differing effects of ability and normative performance goals. Journal of Educational Psychology, 112, 823-840. https://doi. org/10.1037/edu0000393.

*Cianci, A. M., Klein, H. J., \& Seijts, G. H. (2010a). The effect of negative feedback on tension and subsequent performance: The main and interactive effects of goal content and conscientiousness. Journal of Applied Psychology, 95, 618-630. https://doi.org/10.1037/a0019130.

*Cianci, A. M., Schaubroeck, J. M., \& McGill, G. A. (2010b). Achievement goals, feedback, and task performance. Human Performance, 23, 131-154. https://doi.org/10.1080/08959281003621687.

Convington, M. V. (2000). Goal theory, motivation, and school achievement: An integrative review. Annual Review of Psychology, 51, 171-200. https://doi.org/10.1146/0084/6570/00/0171/0200.

*Covington, M. V., \& Omelich, C. L. (1984). Task-oriented versus competitive learning structures: Motivational and performance consequences. Journal of Educational Psychology, 76, 1038-1050. https ://doi.org/10.1037//0022/0663.76.6.1038.

*Crouzevialle, M., \& Butera, F. (2013). Performance-approach goals deplete working memory and impair cognitive performance. Journal of Experimental Psychology: General, 142, 666-679. https ://doi.org/10.1037/a0029632.

*Cury, F., Elliot, A., Sarrazin, P., Da Fonseca, D., \& Rufo, M. (2002). The trichotomous achievement goal model and intrinsic motivation: A sequential mediational analysis. Journal of Experimental Social Psychology, 38, 473-481. https://doi.org/10.1016/S0022-1031(02)00017-3.

*Darnon, C., Butera, F., \& Harackiewicz, J. M. (2007a). Achievement goals in social interactions: Learning with mastery vs. performance goals. Motivation and Emotion, 31, 61-70. https://doi. org/10.1007/s11031-006-9049-2.

Darnon, C., Dompnier, B., Gilliéron, O., \& Butera, F. (2010). The interplay of mastery and performance goals in social comparison: A multiple-goal perspective. Journal of Educational Psychology, 102, 212-222. https://doi.org/10.1037/a0018161.

*Darnon, C., Harackiewicz, J. M., Butera, F., Mugny, G., \& Quiamzade, A. (2007b). Performanceapproach and performance-avoidance goals: When uncertainty makes a difference. Personality and Social Psychology Bulletin, 33, 813-827. https://doi.org/10.1177/0146167207301022.

*Dewar, A. J., Kavussanu, M., \& Ring, C. (2013). The effects of achievement goals on emotions and performance in a competitive agility task. Sport, Exercise, and Performance Psychology, 2, 250-264. https://doi.org/10.1037/a0032291.

*Dickhäuser, C., Buch, S. R., \& Dickhäuser, O. (2011). Achievement after failure: The role of achievement goals and negative self-related thoughts. Learning and Instruction, 21, 152-162. https://doi. org/10.1016/j.learninstruc.2010.01.002.

Duval, S. J., \& Tweedie, R. L. (2000). A nonparametric "trim and fill" method of accounting for publication bias in meta-analysis. Journal of the American Statistical Association, 95, 89-98. https://doi. org/10.2307/2669529.

Dweck, C. S. (1986). Motivational processes affecting learning. American Psychologist, 41, 1040-1048. https://doi.org/10.1037//0003-066X.41.10.1040.

Dweck, C. S., \& Leggett, E. (1988). A social-cognitive approach to motivation and personality. Psychological Review, 95, 256-273. https://doi.org/10.1037//0033-295X.95.2.256.

Dweck, C. S. (2000). Self-theories: Their role in motivation, personality, and development. Philadelphia: Psychology Press.

*Edwards, O. V. (2010). The effect of goal orientation of attention, learning, and metacognitive awareness (Doctoral dissertation). Las Vegas, NV: University of Nevada.

Egger, M., Smith, G. D., Schneider, M., \& Minder, C. (1997). Bias in meta-analysis detected by a simple, graphical test. British Medical Journal, 315, 629-634. https://doi.org/10.1136/bmj.315.7109.629. 
Elliot, A. J. (1999). Approach and avoidance motivation and achievement goals. Educational Psychologist, 34, 169-189. https://doi.org/10.1207/s15326985ep3403_3.

*Elliot, A. J., Cury, F., Fryer, J. W., \& Huguet, P. (2006). Achievement goals, self-handicapping, and performance attainment: A mediational analysis. Journal of Sport and Exercise Psychology, 28, 344-361. https://doi.org/10.1123/jsep.28.3.344.

*Elliot, A. J., \& Harackiewicz, J. M. (1994). Goal setting, achievement orientation, and intrinsic motivation: A mediational analysis. Journal of Personality and Social Psychology, 66, 968-980. https:// doi.org/10.1037/0022-3514.66.5.968.

*Elliot, A. J., \& Harackiewicz, J. W. (1996). Approach and avoidance achievement goals and intrinsic motivation: A mediational analysis. Journal of Personality and Social Psychology, 70, 461-475. https://doi.org/10.1037/0022-3514.70.3.461.

Elliot, A. J., \& McGregor, H. A. (2001). A 2 x 2 achievement goal framework. Journal of Personality and Social Psychology, 80, 501-519. https://doi.org/10.1037//0022-3514.80.3.501.

Elliot, A. J., Murayama, K., \& Pekrun, R. (2011). A 3 x 2 achievement goal model. Journal of Educational Psychology, 103, 632-648. https://doi.org/10.1037/a0023952.

*Elliot, A. J., Shell, M. M., Henry, K. B., \& Maier, M. A. (2005). Achievement goals, performance contingencies, and performance attainment: An experimental test. Journal of Educational Psychology, 97, 630-640. https://doi.org/10.1037/0022-0663.97.4.630.

Elliot, A. J., \& Trash, T. M. (2001). Achievement goals and the hierarchical model of achievement motivation. Educational Psychology Review, 13, 139-156. https://doi.org/10.1023/A:1009057102306.

Elliott, J. (2004). Multimethod approaches in educational research. International Journal of Disability, Development and Education, 51, 135-149. https://doi.org/10.1080/10349120410001687364.

*Escribe, C., \& Huet, N. (2005). Knowledge accessibility, achievement goals, and memory strategy maintenance. British Journal of Educational Psychology, 75, 87-104. https://doi.org/10.1348/00070 $9904 X 19227$.

*Gabriele, A. J., \& Montecinos, C. (2001). Collaborating with a skilled peer: The influence of achievement goals and perceptions of partners' competence on the participation and learning of low-achieving students. The Journal of Experimental Education, 69, 152-178. https://doi. org/10.1080/00220970109600654.

*Gano-Overway, L. A. (2001). The role of task- and ego-involving goals and perceived ability on selfregulatory factors during a simple motor task (Doctoral dissertation). East Lansing, MI: Michigan State University.

*Gelety, L. S. (2010). The social effects of achievement goals (Doctoral dissertation). Pennsylvania: Lehigh University.

*Giannini, J. M., Weinberg, R. S., \& Jackson, A. J. (1988). The effects of mastery, competitive, and cooperative goals on the performance of simple and complex basketball skills. Journal of Sport and Exercise Psychology, 10, 408-417. https://doi.org/10.1123/jsep.10.4.408.

*Graham, S., \& Golan, S. (1991). Motivational influences on cognition: Task involvement, ego involvement, and depth of information processing. Journal of Educational Psychology, 83, 187-194. https ://doi.org/10.1037//0022-0663.83.2.187.

*Haeggberg, D. (2000). The influence of goal orientation on individuals' cognitive, affective, and behavioral reactions to different types of performance feedback, (Doctoral dissertation). Athens, $\mathrm{OH}$ : Ohio University.

*Harackiewicz, J. M., Abrahams, S., \& Wageman, R. (1987). Performance evaluation and intrinsic motivation: The effects of evaluative focus, rewards, and achievement orientation. Journal of Personality and Social Psychology, 53, 1015-1023. https://doi.org/10.1037//0022-3514.53.6.1015.

Hedges, L. V., \& Vevea, J. L. (1998). Fixed- and random-effects models in meta-analysis. Psychological Methods, 3, 486-504. https://doi.org/10.1037//1082-989X.3.4.486.

Higgins, J. P. T., \& Thompson, S. G. (2002). Quantifying heterogeneity in a meta- analysis. Statistics in Medicine, 21, 1539-1558. https://doi.org/10.1002/sim.1186.

*Hole, J. L., \& Crozier, W. (2007). Dispositional and situational learning goals and children's self-regulation. British Journal of Educational Psychology, 77, 773-786. https://doi.org/10.1348/00070 9907X196264.

Huang, C. (2011). Achievement goals and achievement emotions: A meta-analysis. Educational Psychology Review, 23, 359-388. https://doi.org/10.1007/s10648-011-9155-x.

Huang, C. (2012). Discriminant and criterion-related validity of achievement goals in predicting academic achievement: A meta-analysis. Journal of Educational Psychology, 104, 48-73. https://doi. org/10.1037/a0026223. 
Hulleman, C. S., Schrager, S. M., Bodmann, S. M., \& Harackiewicz, J. M. (2010). A meta-analytic review of achievement goal measures: Different labels for the same constructs or different constructs with similar labels? Psychological Bulletin, 136, 422-449. https://doi.org/10.1037//a0018947.

Hunter, J. E., \& Schmidt, F. L. (2000). Fixed effects vs. random effects meta-analysis models: Implications for cumulative research knowledge. International Journal of Selection and Assessment, 8, 275-292. https://doi.org/10.1111/1468-2389.00156.

*Jagacinski, C. M., Kumar, S., \& Kokkinou, I. (2008). Challenge seeking: The relationship of achievement goals to choice of task difficulty level in ego-involving and neutral conditions. Motivation and Emotion, 32, 310-322. https://doi.org/10.1007/s11031-008-9103-3.

*Jagacinski, C. M., Madden, J. L., \& Reider, M. H. (2001). The impact of situational and dispositional achievement goals on performance. Human Performance, 14, 321-337. https://doi.org/10.1207/ S15327043HUP1404_3.

*Johnson, B. F. (2010). Influence of avatar discourse and students' achievement motivation on the adoption of avoidance strategies, interest, self-efficacy, and achievement in computer-based mathematics instruction (Doctoral dissertation). Greeley CO: University of Northern Colorado.

Kanfer, R. (1990). Motivation theory and industrial and organizational psychology. In M. D. Dunette \& L. Houghs (Eds.), Handbook of industrial and organizational psychology (pp. 75-170). San Diego, CA: Psychological Corporation.

*Kavussanu, M., Morris, R. L., \& Ring, C. (2009). The effects of achievement goals on performance, enjoyment, and practice of a novel motor task. Journal of Sports Sciences, 27, 1281-1292. https ://doi.org/10.1080/02640410903229287.

*Koestner, R., Zuckerman, M., \& Koestner, J. (1987). Praise, involvement, and intrinsic motivation. Journal of Personality and Social Psychology, 53, 383-390. https://doi. org/10.1037//0022-3514.53.2.383.

Korn, R. M., \& Elliot, A. (2016). The 2 x 2 standpoints model of achievement goals. Frontiers in Psychology, 7, 1-12. https://doi.org/10.3389/fpsyg.2016.00742.

Kozlowski, S. W. J., \& Bell, B. S. (2006). Disentangling achievement orientation and goal setting: Effects on self-regulatory processes. Journal of Applied Psychology, 91, 900-916. https://doi. org/10.1037/0021-9010.91.4.900.

Latham, G., \& Locke, E. (2007). New developments in and directions for goal-setting research. European Psychologist, 12, 290-300. https://doi.org/10.1027/1016-9040.12.4.290.

*Lawrence, J. S., \& Crocker, J. (2009). Academic contingencies of self-worth impair positivelyand negatively- stereotyped students' performance in performance-goal settings. Journal of Research in Personality, 43, 868-874. https://doi.org/10.1016/j.jrp.2009.05.002.

Linnenbrink, E. A. (2005). The dilemma of performance-approach goals: The use of multiple goal contexts to promote students' motivation and learning. Journal of Educational Psychology, 97, 197-213. https://doi.org/10.1037/0022-0663.97.2.197.

Linnenbrink-Garcia, L., Tyson, D. F., \& Patall, E. A. (2008). When are achievement goal orientations beneficial for academic achievement? A closer look at main effects and moderating factors. Revue Internationale de Psychologie Sociale, 21, 19-70.

Lochbaum, M., \& Gottardy, J. (2015). A meta-analytic review of the approach-avoidance achievement goals and performance relationships in the sport psychology literature. Journal of Sport and Health Science, 4, 164-173. https://doi.org/10.1016/j.jshs.2013.12.004.

*Lovejoy, C. M. (2012). End game effects: Considering the potential benefit of using performanceavoidance goals within an academic achievement goal context (Doctoral dissertation). IL: Northern Illinois University.

*Mangos, P. M., \& Steele-Johnson, D. (2001). The role of subjective task complexity in goal orientation, self-efficacy, and performance relations. Human Performance, 14, 169-186. https://doi. org/10.1207/S15327043HUP1402_03.

* Matthews, W. K. (2007). The effects of the conductor's goal orientation and use of shared performance cues on instrumentalists' self-regulation, motivational beliefs, and performance in large musical ensembles (Doctoral dissertation). Fairfax, VA: George Mason University.

Meece, J. L., Anderman, E. M., \& Anderman, L. H. (2006). Classroom goal structure, student motivation, and academic achievement. Annual Review of Psychology, 57, 487-503. https://doi. org/10.1146/annurev.psych.56.091103.070258.

*Miles, K. (2010). Mastery learning and academic achievement (Doctoral dissertation). Minneapolis, $\mathrm{MN}$ : Walden University. 
*Moos, D. C. (2004). The role of goal structure in undergraduates' use of self-regulatory variables in two hypermedia learning tasks (Master thesis). Maryland: University of Maryland.

* Mousseau, A. C. (2012). Implementing an incremental theory intervention with American Indian youth: Examining the effects on motivation, affect, and stereotype threat, (Doctoral dissertation). Laramie, WY: University of Wyoming.

Murayama, K., \& Elliot, A. J. (2009). The joint influence of personal achievement goals and classroom goal structures on achievement-relevant outcomes. Journal of Educational Psychology, 101, 432-447. https://doi.org/10.1037/a0014221.

*Newman, R. S., \& Schwager, M. T. (1995). Students' help seeking during problem solving: Effects of grade, goal, and prior achievement. American Educational Research Journal, 32, 352-376. https:// doi.org/10.3102/00028312032002352.

Nicholls, J. G. (1978). The development of the concepts of effort and ability, perception of own attainment and the understanding that difficult tasks require more ability. Child Development, 49, 800814. https://doi.org/10.2307/1128250.

Nicholls, J. G. (1984). Achievement motivation: Conceptions of ability, subjective experience, task choice, and performance. Psychological Review, 91, 328-346. https://doi. org/10.1037//0033-295X.91.3.328.

*Niemivirta, M. (2002). Motivation and performance in context: The influence of goal orientations and instructional setting on situational appraisals and task performance. Psychologia, 45, 250-270. https://doi.org/10.2117/psysoc/2002/250.

*Noordzij, G., Van Hooft, E. A. J., Van Mierlo, H., Van Dam, A., \& Born, M. P. H. (2013). The effects of learning-goal orientation training on self-regulation: A field experiment among unemployed job seekers. Personnel Psychology, 66, 723-755. https://doi.org/10.1111/peps.12011.

*Nordstrom, C. R., Wendland, D., \& Williams, K. B. (1998). "To err is human": An examination of the effectiveness of error management training. Journal of Business and Psychology, 12, 269-282. https://doi.org/10.1023/A:1025019212263.

*Ntoumanis, N., Thogersen-Ntoumani, C., \& Smith, A. L. (2009). Achievement goals, self-handicapping, and performance: A 2x2 achievement goal perspective. Journal of Sports Sciences, 27, 1471-1482. https://doi.org/10.1080/02640410903150459.

Pahljina-Reinić, R., \& Kolić-Vehovec, S. (2017). Average personal goal pursuit profile and contextual achievement goals: Effects on students' motivation, achievement emotions, and achievement. Learning and Individual Differences, 56, 167-174. https://doi.org/10.1016/j.lindif.2017.01.020.

Payne, S. C., Youngcourt, S. S., \& Beaubien, J. M. (2007). A meta-analytic examination of the goal orientation nomological net. Journal of Applied Psychology, 92, 128-150. https://doi. org/10.1037/0021-9010.92.1.128.

Rawsthorne, L. J., \& Elliot, A. J. (1999). Achievement goals and intrinsic motivation: A meta-analytic review. Personality and Social Psychology Review, 3, 326-344. https://doi.org/10.1207/s1532 7957pspr0304_3.

*Reinboth, M., \& Duda, J. L. (2016). Effects of competitive environment and outcome on achievement behaviors and well-being while engaged in a physical task. Sport, Exercise, and Performance Psychology, 5, 324-336. https://doi.org/10.1037//spy000075.

Rosenthal, R. (1979). The "file drawer problem" and tolerance for null results. Psychological Bulletin, 86, 638-641. https://doi.org/10.1037/0033/295X.96.2.341.

*Rusk, N. (2011). Learning goals for emotion regulation: A randomized intervention study (Doctoral dissertation). Boston, MA: Tufts University.

Schmidt, F. L., Oh, I. S., \& Hayes, T. L. (2009). Fixed-versus random-effects models in meta-analysis: Model properties and an empirical comparison of differences in results. British Journal of Mathematical and Statistical Psychology, 62, 97-128. https://doi.org/10.1348/0007/11007X255327.

Senko, C., \& Dawson, B. (2017). Performance-approach goal effects depend on how they are defined: Meta-analytical evidence from multiple educational outcomes. Journal of Educational Psychology, 109, 574-598. https://doi.org/10.1037/edu0000160.

*Senko, C., Durik, A., Patel, L., Lovejoy, C. M., \& Valentiner, D. (2013). Performance-approach goal effects on achievement under low versus high challenge conditions. Learning and Instruction, 23, 60-68. https://doi.org/10.1016/j.learninstruc.2012.05.006.

Senko, C., \& Harackiewicz, J. M. (2002). Performance goals: The moderating roles of context and achievement orientation. Journal of Experimental Social Psychology, 38, 603-610. https://doi. org/10.1016/S0022-1031(02)00503-6. 
*Senko, C., \& Harackiewicz, J. M. (2005). Achievement goals, task performance, and interest: Why perceived goal difficulty matters. Personality and Social Psychology Bulletin, 31, 1739-1753. https:// doi.org/10.1177/014616720528112.

Senko, C., Hulleman, C. S., \& Harackiewicz, J. M. (2011). Achievement goal theory at the crossroads: Old controversies, current challenges, and new directions. Educational Psychologist, 46, $26-47$. https://doi.org/10.1080/00461520.2011.538646.

Senko, C., \& Tropiano, K. L. (2016). Comparing three models of achievement goals: Goal orientations, goal standards, and goal complexes. Journal of Educational Psychology, 108, 1178-1192. https:// doi.org/10.1037/edu0000114.

Sisk, V. F., Burgoyne, A. P., Sun, J., Butler, J. L., \& Macnamara, B. N. (2018). To what extent and under which circumstances are growth mind-sets important to academic achievement? Two meta-analyses. Psychological Science, 29(4), 549-571. https://doi.org/10.1177/0956771773 904.

*Song, H. D. (2004). The effects of goal-oriented contexts and peer group compositions on intrinsic motivation and problem solving (Doctoral dissertation). PA: The Pennsylvania State University.

*Steele-Johnson, D., Beauregard, R. S., Hoover, P. B., \& Schmidt, A. M. (2000). Goal orientation and task demand effects on motivation, affect, and performance. Journal of Applied Psychology, 85, 724-738. https://doi.org/10.1037//0021-9010.85.5.724.

*Steele-Johnson, D., Heintz, P., Jr., \& Mille, C. E. (2008). Examining situationally induced state goal orientation effects on task perceptions, performance, and satisfaction: A two-dimensional conceptualization. Journal of Applied Social Psychology, 38, 334-365. https://doi.org/10.111 1/j.1559-1816.2008.00308.x.

*Stout, J. G. (2013). Mastering one's destiny: Mastery goals promote feeling challenge and success despite social identity threat. Personality and Social Psychology Bulletin, 39, 748-762. https:// doi.org/10.1177/0146167213481067.

*Turner, L. A., Johnson, R. B., \& Pickering, S. (1996). Effect of ego and task instructions on cognitive performance. Psychological Reports, 78, 1051-1058. https://doi.org/10.2466/pr0.1996.78.3.1051.

Urdan, T., \& Mestas, M. (2006). The goals behind performance goals. Journal of Educational Psychology, 98, 354-365. https://doi.org/10.1037/0022-0663.98.2.354.

Utman, C. (1997). Performance effects of motivational state: A meta-analysis. Personality and Social Psychology Review, 1, 170-182. https://doi.org/10.1207/s15327957pspr0102_4.

*Van Hooft, E. A. J., \& Noordzij, G. (2009). The effects of goal orientation on job-search and reemployment: A field experiment among unemployed job seekers. Journal of Applied Psychology, 94, 1581-1590. https://doi.org/10.1037/a0017592.

Van Mierlo, H., \& Van Hooft, E. A. J. (2015). A group-level conceptualization of the $2 \times 2$ achievement goal framework: Antecedents and motivational outcomes. Group and Organization Management, 40, 776-808. https://doi.org/10.1177/1059601115592990.

Van Yperen, N. W., Blaga, M., \& Postmes, T. (2014). A meta-analysis of self-reported achievement goals and non self-report performance across three achievement domains (work, sports, and education). PLoS ONE, 9, e93594. https://doi.org/10.1371/journal.pone.0093594.

Van Yperen, N. W., Blaga, M., \& Postmes, T. (2015). A meta-analysis of the impact of situationally induced achievement goals on task performance. Human Performance, 28, 165-182. https://doi. org/10.1080/08959285.2015.1006772.

*Van Yperen, N. W., Elliot, A. J., \& Anseel, F. (2009). The influence of mastery-avoidance goals on performance improvement. European Journal of Social Psychology, 39, 932-943. https://doi. org/10.1002/ejsp.590.

VandeWalle, D. (1997a). Development and validation of a work domain goal orientationinstrument. Educational and Psychological Measurement, 57, 995-1015. https://doi.org/10.1177/00131 64497057006009.

VandeWalle, D. (1997b). Development and validation of a work domain goal orientation instrument. Educational and Psychological Measurement, 57, 995-1015. https://doi.org/10.1177/00131 64497057006009.

Wirthwein, L., Sparfeldt, J. R., Pinquart, M., Wegerer, J., \& Steinmayr, R. (2013). Achievement goals and academic achievement: A closer look at moderating factors. Educational Research Review, 10, 66-89. https://doi.org/10.1016/j.edurev.2013.07.001. 
Publisher's Note Springer Nature remains neutral with regard to jurisdictional claims in published maps and institutional affiliations.

Gera Noordzij is associate professor at Erasmus University Rotterdam the Netherlands: Erasmus University College and Department of Psychology, Education and Child Studies. Her research interest is in improving individual well-being by means of interventions, and education. Specific topics within this theme include achievement goal orientation, resilience and mental health, inequality in education, and 'future-proof' teaching and learning environments.

Lisenne Giel is a PhD-student at Erasmus University Rotterdam the Netherlands: Erasmus University College and Department of Psychology, Education and Child Studies. Her research interest is in the fit between students and their learning environment. Specific topics within this theme include educational inequalities, mental health, and well-being.

Heleen van Mierlo is assistant professor at Erasmus University Rotterdam the Netherlands: Department of Psychology, Education and Child Studies. Her research interest is in regulatory processes in groups and teams. Specific topics within this theme include goal setting and achievement goal orientation, team autonomy, conflict management and methodological issues involved in measuring group-level constructs. 